\title{
The beneficial effects of nutraceuticals and natural products on small dense LDL levels, LDL particle number and LDL particle size: a clinical review
}

Sepide Talebi ${ }^{1,2}$, Mohammad Bagherniya ${ }^{2}$, Stephen L. Atkin ${ }^{3}$, Gholamreza Askari ${ }^{4}$, Hossein M. Orafai ${ }^{5}$ and Amirhossein Sahebkar ${ }^{6,7,8^{*}}$

\begin{abstract}
Cardiovascular diseases (CVDs) are globally the major causes of morbidity and mortality. Evidence shows that smaller and denser low-dense lipoprotein (sdLDL) particles are independent atherogenic risk factors for CVD due to their greater susceptibility to oxidation, and permeability in the endothelium of arterial walls. sdLDL levels are an independent risk factor and of more predictive value than total LDL-C for the assessment of coronary artery disease and metabolic syndrome. Functional food ingredients have attracted significant attention for the management of dyslipidemia and subsequently increase cardio-metabolic health. However, to date there is no study that has investigated the effect of these bioactive natural compounds on sdLDL levels. Therefore, the aim of the present review is to summarize the evidence accrued on the effect of special dietary ingredients such as omega-3 polyunsaturated fatty acids, nutraceuticals and herbal medicines on the levels of sdLDL, LDL particle number, and LDL particle size. Based on the results of the existing clinical trials this review suggests that natural products such as medicinal plants, nutraceuticals and omega-3 fatty acids can be used as adjunct or complementary therapeutic agents to reduce sdLDL levels, LDL particle numbers or increase LDL particle size and subsequently may prevent and treat CVD, with the advantage that theses natural agents are generally safe, accessible, and inexpensive.
\end{abstract}

Keywords: Phytochemical, Medicinal plant, Nutrition, Lipoprotein, Atherosclerosis

\section{Introduction}

Cardiovascular diseases (CVDs) are a global problem and the leading cause of morbidity and mortality [1]. It is projected that the prevalence of death from CVDs will be greater than 23.6 million people by 2030 [2]. Multiple risk factors, including unhealthy diet, physical inactivity,

\footnotetext{
* Correspondence: sahebkara@mums.ac.ir; amir_saheb2000@yahoo.com ${ }^{6}$ Halal Research Center of IRI, FDA, Tehran, Iran

${ }^{7}$ Biotechnology Research Center, Pharmaceutical Technology Institute, Mashhad University of Medical Sciences, Mashhad, Iran

Full list of author information is available at the end of the article
}

diabetes, dyslipidemias, and hypertension are considered to be modifiable factors in CVD [3]. It is well known that progression of CVD and increased atherosclerotic risk are positively linked with dyslipidemia. Hence, optimal levels of lipid profile play an important role in reducing atherosclerotic process [4].

LDL-C is one type of lipoprotein that composed of a heterogeneous group of molecules with different sizes, density, lipid composition and physical properties. Smaller and denser LDL particles are considered as an atherogenic risk factor for CVD due to their greater susceptibility to oxidation, and their permeability through

(c) The Author(s). 2020 Open Access This article is licensed under a Creative Commons Attribution 4.0 International License, which permits use, sharing, adaptation, distribution and reproduction in any medium or format, as long as you give appropriate credit to the original author(s) and the source, provide a link to the Creative Commons licence, and indicate if changes were made. The images or other third party material in this article are included in the article's Creative Commons licence, unless indicated otherwise in a credit line to the material. If material is not included in the article's Creative Commons licence and your intended use is not permitted by statutory regulation or exceeds the permitted use, you will need to obtain permission directly from the copyright holder. To view a copy of this licence, visit http://creativecommons.org/licenses/by/4.0/ The Creative Commons Public Domain Dedication waiver (http://creativecommons.org/publicdomain/zero/1.0/) applies to the data made available in this article, unless otherwise stated in a credit line to the data. 
the endothelium of arterial walls [5, 6]. Large buoyant LDL particles (diameter $\geq 25 \mathrm{~nm}$ ) have been considered as phenotype pattern A and small, dense LDL particles with sizes $19.0-20.5 \mathrm{~nm}$ have been considered as phenotype pattern B [7-9]. The positive link between individuals with high triglycerides and low HDL-C concentrations and LDL pattern B has been established, which are the features of the metabolic syndrome [10]. Small dense low-density lipoprotein (sdLDL) particles are a subfraction of LDL that are characterized by changes in their chemical content, and they are free of cholesterol and cholesterol ester, as well as having a decrease in phospholipid content, whilst the triglyceride content remains unchanged [11]. sdLDL is produced by very low-density lipoproteins (VLDL) in triglyceride-rich conditions derived from the liver. VLDL particles are initially converted to LDL class III and IV by the lipoprotein lipase (LPL) enzyme. Subsequently, the enzyme of cholesteryl ester transfers protein (CETP) with the help of hepatic lipase (HL) transfer TG to sdLDL particles leading to increased levels of sdLDL particles. At low TG levels, VLDL particles are converted to intermediate-density lipoprotein (IDL) and large LDL subclasses (Fig. 1) [5, 12]. Previous studies have shown that sdLDL levels are an independent risk factor and more predictive than total LDL-C for the assessment of coronary artery disease $[13,14]$ and metabolic syndrome [15]. sdLDL particles play a crucial role in the etiology of ischemic heart disease (IHD) and coronary heart disease (CHD) $[16,17]$. Guidelines of the Association of Clinical Endocrinologists (AACE) recommended that LDL particle number is a more powerful tool to predict CVD events than LDL particle size or sdLDL [10]. Overall, measurement of sdLDL or LDL particle number together with the lipid profile (LDL-C, triglycerides, HDL$\mathrm{C}$ and cholesterol) can be useful in the evaluation and management of CVD [10, 18].

One of the most important therapeutic targets for reducing CVD risk is to improve sdLDL-C levels [18]. Life-style changes emphasizing a healthy diet could play an important role in decreasing the atherogeneity of the lipid profile [19-21]. Functional food ingredients have attracted significant attention as natural products for the management of dyslipidemia and subsequently increase cardio-metabolic health [22-28]. Although nutraceuticals and herbal medicine have been previously studied as a non-pharmacological management of dyslipidemia [29-35], greater clarity on the effects of these bioactive natural compounds in improving sdLDL for the reduction in the relative risk of CVD is needed. To date, there is no study that has investigated the effect of these bioactive natural compounds on sdLDL levels. Therefore, the aim of the present review is to summarize the evidence accrued on the effect of special diet ingredients such as n-3 polyunsaturated fatty acids, nutraceuticals and herbal medicines on the levels of sdLDL, LDL particle number, and LDL particle size.

\section{Search strategy}

The present narrative review was performed based on the PRISMA guidelines. The databases of PubMed, Web of Science, Google Scholar, and Scopus were searched up to August 2019 and limited to English language. Search strategies were included the following keywords in titles abstracts: (medicinal plants OR herbal bioactive OR bioactive natural compounds OR nutraceutical); AND (random OR randomized OR randomly OR randomization OR "randomized controlled trial" OR "randomized trial" OR "randomized study" OR "random number" OR placebo) AND (Small dense low-density lipoprotein OR sdLDL OR "LDL particle number" OR "LDL particle size" OR "LDL subfraction").

\section{Phytosterols and vegetable oils}

Phytosterols (plant sterols and stanol esters) have been reported to prevent the development of several chronic diseases including cancer, CVD and diabetes [36-39]. The results of previous meta-analyses indicated that phytosterols might improve lipid profile levels [40-42]. Phytosterols may decrease oxidized LDL and can be considered as an atherogenic modification for LDL. In a cross-over controlled trial, 25 healthy male volunteers were recruited to ingest $25 \mathrm{~mL} / \mathrm{d}$ raw low-polyphenolcontent olive oil (LPCOO; $366 \mathrm{mg} / \mathrm{kg}$ ) or highpolyphenol-content olive oil (HPCOO; $2.7 \mathrm{mg} / \mathrm{kg}$ ) for 3 weeks, separated by a two-week washout period. At the end of the study, in comparison to the baseline and LPCOO group, HPCOO intervention resulted in a significant reduction in small LDL particles. Conversely compared to baseline, LPCOO significantly increased small LDL particles [43]. In a trial study, 108 metabolic syndrome patients were randomized to receive one of two plant sterol-enriched yogurt mini drinks that contained $4 \mathrm{~g}$ phytosterols, or a yogurt beverage without phytosterols (control). After 2 months intervention, phytosterol supplementation significantly reduced sdLDL levels in the intervention group compared with the control group [44]. In another study, 59 children between 4.5-15.9 years of age were divided into 2 groups: (i) 25 subjects with a LDL-C $\geq(130 \mathrm{mg} / \mathrm{dl}$ to receive a yogurtdrink enriched with $2 \mathrm{~g}$ of plant sterols for 6 to 12 months (intervention group) or (ii) 34 subjects with a LDL-C $<130 \mathrm{mg} / \mathrm{dl}$ (control group). Results indicated that plant sterol consumption reduced sdLDL in the intervention group compared to the control group in which they were unchanged [45]. In a previous study, 56 healthy participants received a diet that contained high amounts of saturated fat for 2 weeks; and subsequently 


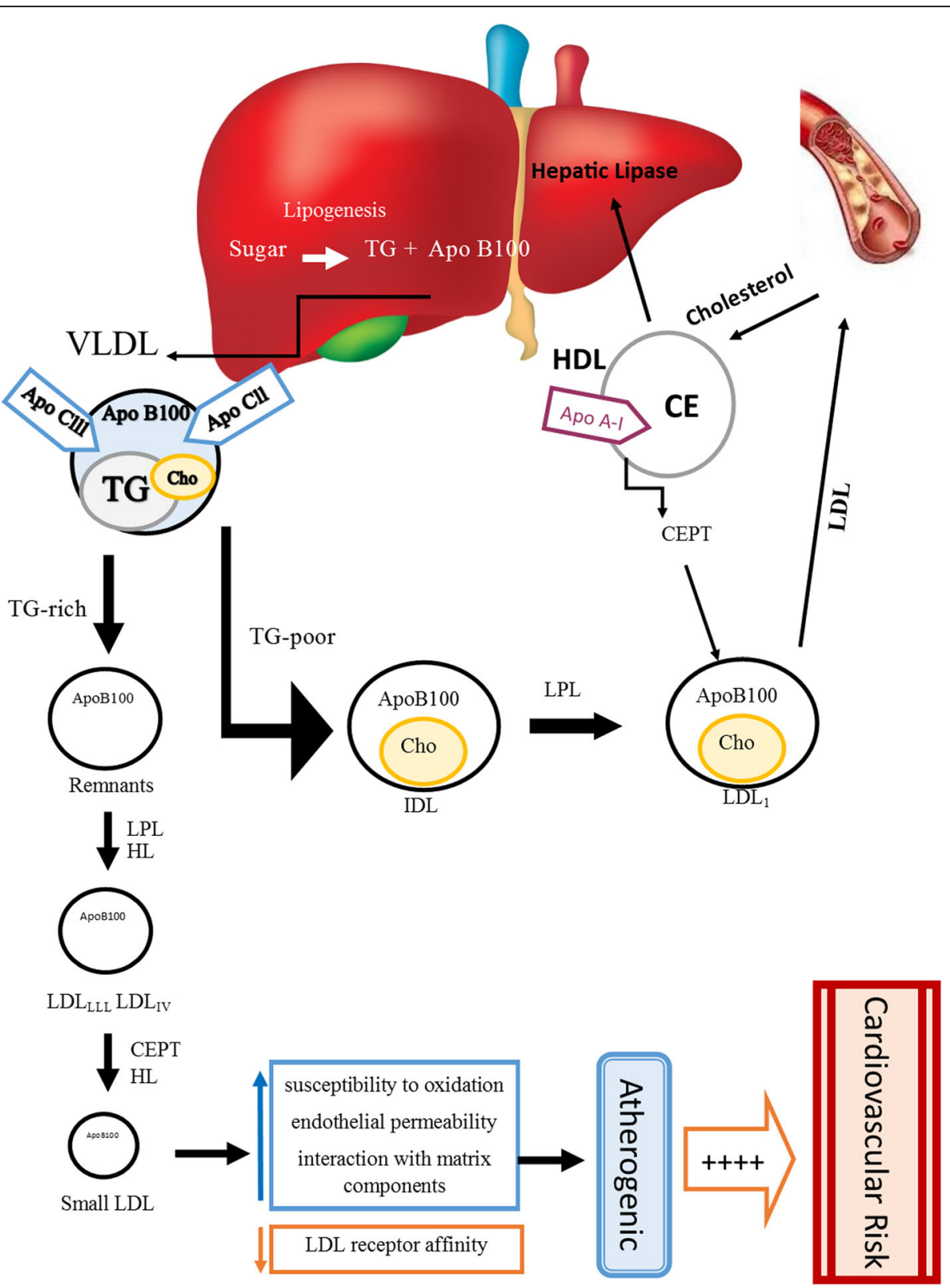

Fig. 1 Schematic summary of pathways of endogenous lipid metabolism and pathways of the atherogenic and anti-atherogenic lipoproteins. sdLDL: small dense low density lipoprotein, Apo: apolipoprotein, VLDL: very-low-density lipoprotein, IDL: intermediate-density lipoprotein, LDL: low-density lipoprotein; LDL-R: low-density lipoprotein receptor, HDL: high-density lipoprotein, TG: triglycerides, CE: cholesteryl esters, +: increased risk

were randomized to one of three dietary intervention treatments; refined olive oil, rapeseed oil or sunflower oil as the principal source of fat for 4 weeks. The results showed that during the oil diet phase, LDL size significantly reduced though differences between groups were not significant and oil consumption did not significantly change LDL size variation [46]. In a recent report, 40 healthy subjects were randomly allocated to drink an inositol-enriched beverage (IEB) that contained inositols $2.23 \mathrm{~g}$ in $250 \mathrm{ml}$ or a sucrose- sweetened beverage (SB) twice daily for 12 weeks. The study showed that those subjects in the IEB arm had a significant increase in LDL particle size compared to the SB group [42]. Shrestha et al. conducted a randomized, crossover study, in which 33 healthy adults were allocated to treatment cookies $(7.68 \mathrm{~g} / \mathrm{d}$ psyllium and $2.6 \mathrm{~g} / \mathrm{d}$ plant sterols) and a placebo cookie $(0 \mathrm{~g}$ psyllium and plant sterols) for 4 weeks (each separated by a 3-week washout period). At the end of the study, psyllium and plant sterol cookies reduced the 
medium-small LDL particles, and markedly increased mean and peak LDL particle sizes compared with placebo $[47,48]$. In a randomized double-blind clinical trial, 54 adults with $\mathrm{LDL}-\mathrm{C}$ level $\geq 3.33 \mathrm{mmol} / \mathrm{L}$ were randomized into two groups to receive four capsules of phytosterol esters ( $2.6 \mathrm{~g} /$ day phytosterol esters) or placebo (canola oil) per day for 12 weeks. At the end of the study the proportion of LDL, mean and peak LDL particle sizes did not differ between groups [49]. Matvienko et al. conducted a clinical trial study in which 34 men with moderate hypercholesterolemia and hypertriglyceridemia were randomly divided into two groups to consume ground beef with $2.7 \mathrm{~g}$ of phytosterols that included 67\% sterol esters and 33\% free sterols, or ground beef alone as the control group. After 4 weeks of intervention there were no differences between groups for small LDL particle and LDL peak particle size, though there was a trend for mean LDL particle number to decrease in the phytosterol treated group compared with the control group [50]. In another trial, 28 participants with familial combined hyperlipidemia (FCHL) and elevated triacylglycerols consumed $2.5 \mathrm{~g}$ plant stanol ester-enriched margarine per day or margarine without stanols as control for 3 weeks. No cholesterol-lowering drugs were used 2 weeks before and during the study. At the end of the study after stanol supplementation the number of total LDL particles decreased, but sdLDL particles did not differ compared with baseline [51]. Utarwuthipong et al. [52] also reported a study of 16 hyperlipidaemic women who were recommended a National Cholesterol Expert Panel diet (55\% carbohydrate, $15 \%$ protein, $30 \%$ fat, $<300 \mathrm{mg} /$ day of cholesterol) as a run in baseline diet for 8 weeks. All participants were subsequently randomized into four treatment groups to take either diet plus SBO (soybean oil, 20\% of total energy), or diet plus RBO (rice bran oil, $20 \%$ of total energy) or diet plus PO (palm oil, $20 \%$ of total energy) or diet plus RBO/PO (20\% of total energy as mixture of (3:1) RBO/PO). Every 10 weeks, they were crossed over to another group and therefore they participated for a total of 48 weeks. The sdLDL particles were measured via a sequential ultracentrifugation technique. Results showed that $\mathrm{SBO}$ and $\mathrm{RBO} / \mathrm{PO}$ significantly reduced sdLDLcholesterol levels, though PO significantly increased sdLDL-cholesterol levels and RBO did not differ compared to the control diet (Table 1). Overall, in almost all of the studies reviewed here, vegetable oils and phytosterols showed promising effects on sdLDL-cholesterol levels, and LDL-particle size. In 4 studies out of 6 , sdLDL was decreased after the intervention with vegetable oils and phytosterols, and in 2 studies out of 4, LDL particle size increased after the intervention. In the 2 studies that
sdLDL did not decrease and in one study that LDL particle size did not change, LDL particle number significantly decreased.

\section{Eicosapentaenoic acid and docosahexaenoic acid}

Eicosapentaenoic acid (EPA) and docosahexaenoic acid (DHA) derived from alpha-linolenic acid (ALA) are one of the family of essential fatty acids derived from the diet, as they cannot be made endogenously, that are involved in cell membrane stability [53]. It is suggested that EPA and DHA may have beneficial effects on the treatment of NAFLD [54], diabetes [55] and cardiovascular disease [56, 57]. However, there has been concern whether $n-3$ fattyacid enhances the susceptibility of LDL to oxidation, though the data remains inconclusive [58-60]. In a comparative study, $5 \mathrm{~g} /$ day fish oil supplement containing 1.9$2.2 \mathrm{~g}$ EPA and $1.1 \mathrm{~g}$ DHA were given to 210 healthy adults for 6 weeks. At post intervention, there was no significant change in LDL particle size compared to baseline [61]. Oelrich et al. conducted a clinical trial in which 60 subjects with moderate hypertriglyceridemia randomly were divided into 4 groups to consume $4 \mathrm{~g} /$ day fish oil supplementation in three formulations ((i) 90\% TG formulation, (ii) $60 \%$ TG formulation, or (iii) $0 \%$ TG ethyl esters) with a soy oil supplement as the control group. LDL particles were assessed by gradient gel electrophoresis. After 12 weeks intervention, in all fish oil groups, four particle sizes in terms of $\mathrm{LDL}_{1}, \mathrm{LDL}_{2}$, and $\mathrm{LDL}_{3}$ significantly increased in comparison to the baseline, though the concentration of $\mathrm{LDL}_{4}$ did not differ [62]. In a double blind, placebo controlled trial, 42 diabetic patients with moderate hypercholesterolemia were treated with corn oil capsules $(4 \mathrm{~g} /$ day) for 4 weeks, then they were randomly divided into two groups to consumed fish oil tablets (2.6 g EPA and DHA, plus $13.4 \mathrm{mg}$ vitamin $\mathrm{E}$ ), or corn oil tablets (1 $\mathrm{g}$ corn oil plus $13.4 \mathrm{mg}$ vitamin E) four times a day. Results of this study showed that sdLDL particles did not significantly change in the EPA/DHA intervention group compared with control group [63]. In a randomized crossover trial, 20 hypertensive adults ingested four capsules of fish oil (4 $\mathrm{g}$ per day) or corn oil tablet as a placebo for 6 weeks that resulted in an increase in LDL size $(+0.16 \mathrm{~nm})$ in the fish oil group [64]. In another clinical trial, 121 healthy individuals with normal lipid profiles were randomly assigned to take $600 \mathrm{mg} /$ day EPA, $1800 \mathrm{mg} /$ day EPA, $600 \mathrm{mg} /$ day DHA or $6 \mathrm{~g} /$ day olive oil that was used as the comparator. After 6 weeks of supplementation, sdLDL was unchanged between and within the four groups [65]. Satoh et al. [66] randomized 44 obese participants with $\geq 2$ risk factors of metabolic syndrome into two groups; diet plus $1.8 \mathrm{~g} /$ day EPA (intervention group) or diet alone (control group) for 3 months. The diet was that of the Japan Atherosclerosis Society Guidelines and included $60 \%$ of total energy from carbohydrates, $15-20 \%$ from protein and $20-25 \%$ from fat 


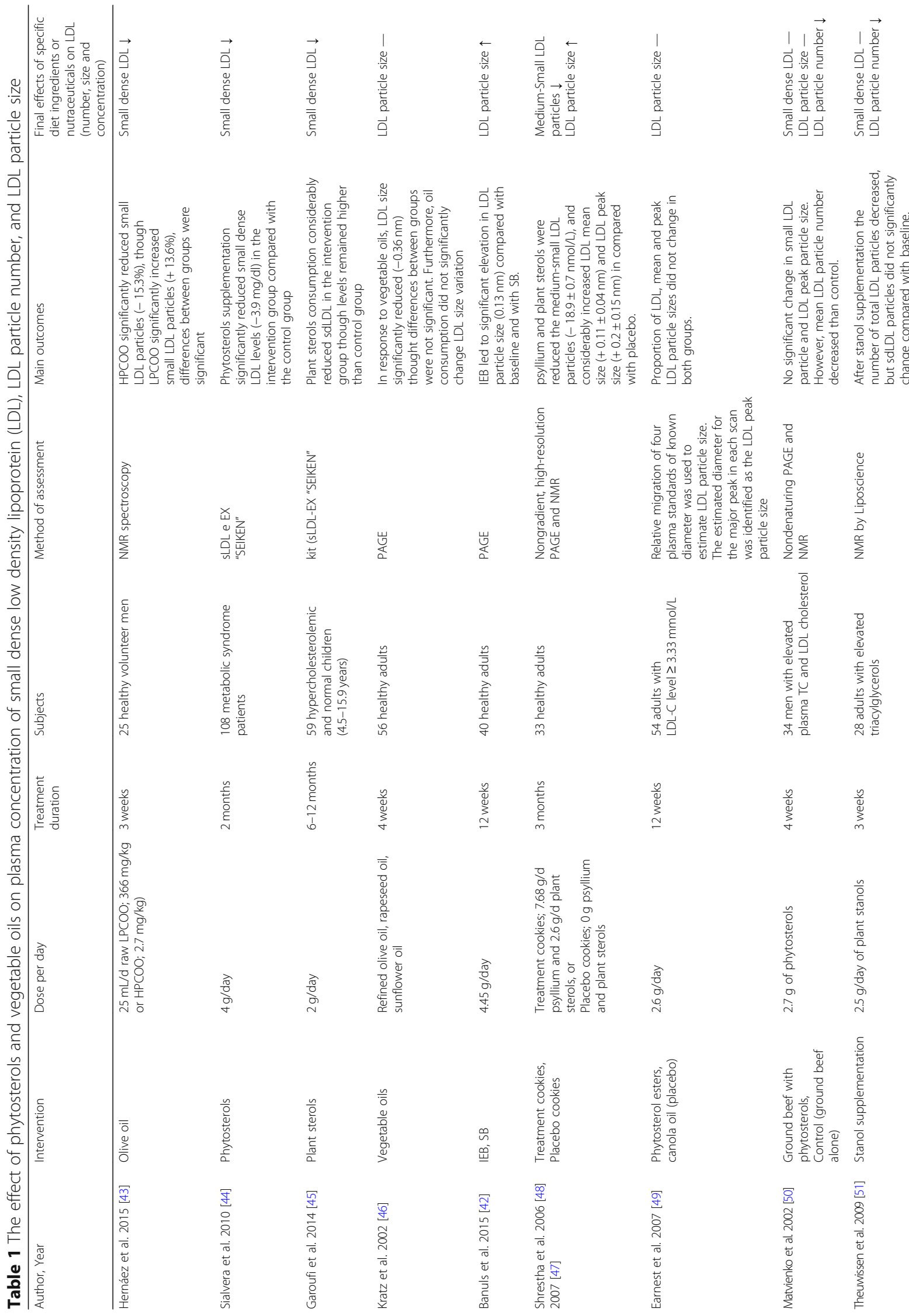




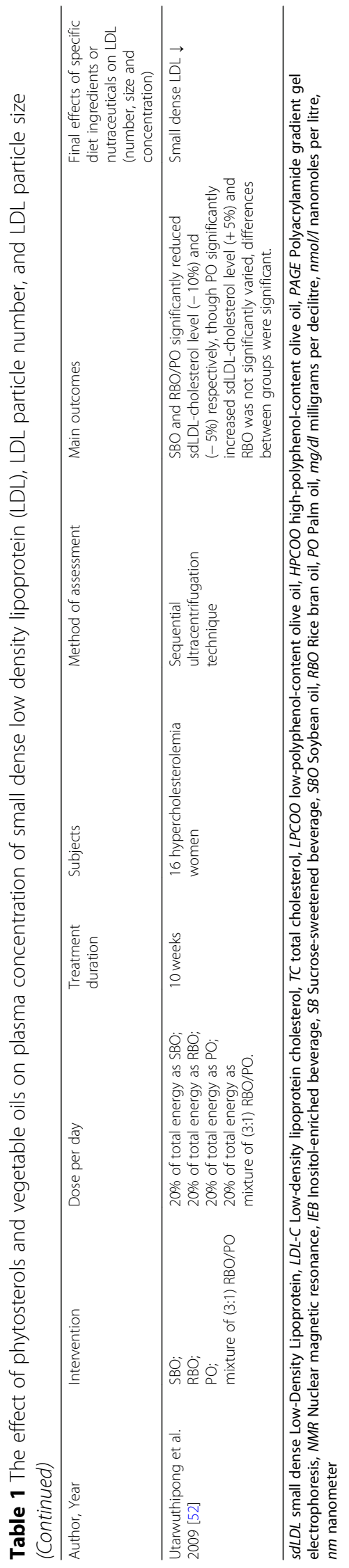


by following the ratio 3:4:3 as polyunsaturated, monounsaturated and saturated fatty acids, respectively. In addition, the daily diet was based on $25 \mathrm{kcal} / \mathrm{kg}$ of ideal body weight. Results indicated that sdLDL and sdLDL proportion significantly decreased in the EPA group compared with baseline, but did not differ between the two groups. In another study, 59 overweight adults with mild hypercholesterolemia were randomized to consume $4 \mathrm{~g}$ EPA every day, or DHA or olive oil as the comparative control for 6 weeks. There was no significant difference in LDL particle size between and within groups; however, after adjustment for baseline values, LDL particle size significantly increased $(0.25 \pm 0.08 \mathrm{~nm})$ in the DHA group compared with olive oil (placebo) [67]. In a study of 34 healthy or mildly hyperlipidemic men who were randomized to two groups: (i) $7.5 \mathrm{~g} /$ day DHA ( $3 \mathrm{~g}$ /day DHA), (ii) $7.5 \mathrm{~g}$ /day olive oil (comparator). After 90 days of intervention, participants who consumed DHA had fewer small dense LDL particles though this did not differ compared to the control, though there was a significant increase in mean LDL particle compared with baseline [68]. In another clinical trial, 57 subjects with below average levels of HDL were given either DHA capsules (1.52 g DHA per day) or olive oil capsules as a control group for 6 weeks. Results revealed that DHA had no effect on sdLDL though the percentage of cholesterol in the small dense LDL was significantly decreased by DHA in comparison with the control group [69]. In another crossover study, 15 healthy adult males were randomized into 2 groups to receive $10 \mathrm{~g}$ flaxseed oil (5.49g of $\alpha$-Linolenic acid) or $10 \mathrm{~g}$ corn oil $(0.09 \mathrm{~g}$ of $\alpha$-Linolenic acid) as placebo for 12 weeks. Results showed that in the intervention group, the concentration of sd-LDL significantly reduced after 4 and 12 weeks of flaxseed oil supplementation compared with baseline $(-25.8 \%$ and $-21.2 \%$ respectively). In addition, sd-LDL concentrations decreased significantly compared with the control group after 4 weeks [70]. In a study of 56 patients without known coronary heart disease, they were assigned to receive $5.2 \mathrm{~g}$ flaxseed oil ( $3 \mathrm{~g} / \mathrm{d}$ of ALA), or 5.2 $\mathrm{g}$ of olive oil as control per day for 26 weeks. At the end of the study there was no effect of flaxseed oil on atherogenic LDL subfractions ( $\mathrm{LDL}_{3}$ and $\left.\mathrm{LDL}_{4}\right)$; however, flaxseed oil significantly increased the less atherogenic LDL subfractions $\left(\mathrm{LDL}_{1}\right.$ and $\left.\mathrm{LDL}_{2}\right)$ as compared to the control olive oil [71] (Table 2). Overall, in 3 out of 5 studies reviewed here, LDL particle size significantly increased after the intervention; however, in 2 studies out of 6 studies sdLDL was significantly decreased though other studies did not find any significant changes.

\section{Fruits}

Fruits are a rich source of flavonoids, polyphenols, fiber and have antioxidant properties that have been reported to have beneficial effects on various metabolic disorders
[72-75]. In a randomized 3-period crossover study design, 45 overweight participants with baseline LDL entered into a 2-week run-in period taking an average American diet (51\% carbohydrate, $16 \%$ protein, $34 \%$ fat, $13 \%$ saturated fat). Following a run-in period, participants were randomly allocated to receive either an avocado diet (one fresh Hass avocado contained $136 \mathrm{~g}$ fruit pulp and $13 \mathrm{~g}$ monounsaturated fatty acids (MUFA)) or a low-fat diet (59\% carbohydrate, $16 \%$ protein, $24 \%$ fat, $7 \%$ saturated fat contained grains instead of SFA) or a moderate-fat diet ( $49 \%$ carbohydrate, $16 \%$ protein, $34 \%$ fat, $6 \%$ saturated fat that contained high oleic acid oils, sunflower oil and canola oil). After a 5 week period, subjects were washed out over a 2-week period and crossed over for each of the interventions. Results showed that LDL particle number and small dense LDL cholesterol number were significantly lower following the AV diet compared with baseline. LDL particle size was reduced in all diets, but compared with the LF diet the AV diet led to a significant rise in LDL particle size [76]. In a controlled, 3-arm, crossover study, 31 overweight or obese subjects with a fasting glucose that ranged 5.0$6.4 \mathrm{mmol} / \mathrm{L}$ were randomized to either Half-Avocado group who received $68 \mathrm{~g} / \mathrm{d}$ fresh avocado or WholeAvocado contained $136 \mathrm{~g}$ avocado per day or control group (without any avocado). After $6 \mathrm{~h}$ following ingestion, lipoprotein particles were measured by NMR spectra of frozen plasma. Those that consumed a whole avocado showed a significant reduction in sdLDL particles compared with the control [77]. In a clinical trial, 27 subjects with metabolic syndrome were divided into either strawberry or control groups. The strawberry group received 2 cups of strawberry beverage plus 2 cups of water while the control group were given only 4 cups of water per day Following strawberry supplementation there was a significant reduction in the concentration of small LDL particles compared to control; however, LDL mean particle size was unchanged between the two groups [78]. In a recent study, 60 subjects with elevated lipid profiles were randomly assigned to either low-dose freeze-dried strawberries (FDS) [LD-FDS; $25 \mathrm{~g}$ strawberries with 2 cups of water] or low-dose control [LD-C; $4 \mathrm{~g}$ of fiber plus $20 \mathrm{~g}$ of cane sugar with 2 cups of water] or high-dose FDS [HD-FDS; $50 \mathrm{~g}$ strawberries with 2 cups of water] or 4) high-dose control [HD-C; $8 \mathrm{~g}$ of fiber plus $36 \mathrm{~g}$ of cane sugar with 2 cups of water] for 12 weeks. Results showed that, the HD-FDS diet significantly decreased small LDL particles compared with the HD-C diet, and this differed significantly compared to the LD-FDS diet [79]. In a randomized cross-over design, 20 obese adults were randomized into two groups and followed for 3 weeks. The intervention group received $80 \mathrm{~g}$ strawberry powder four times daily, the control group were given a strawberry flavoured 


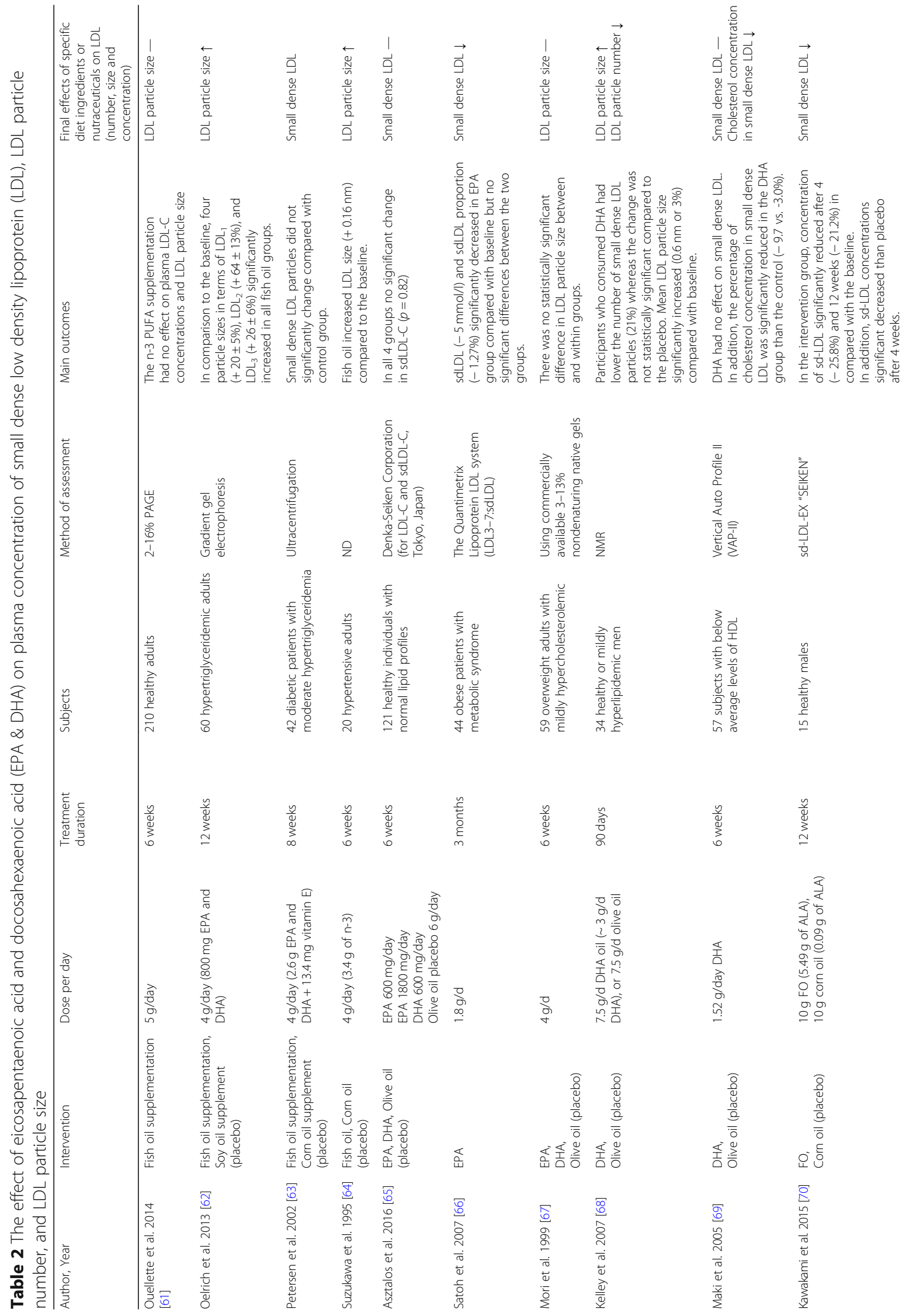




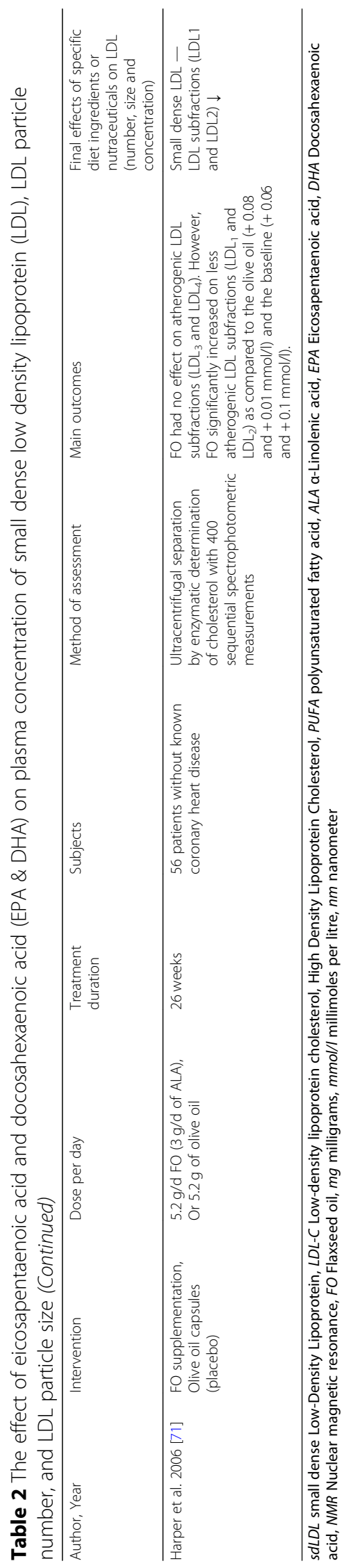


preparation dyed with red food color. The results showed that LDL particle size significantly increased in the intervention group in comparison to the control group; however, the strawberry diets had no effect on the concentrations of small LDL [80]. In an another cross-over study, 24 obese adults were randomized to either the intervention group ( $46 \mathrm{~g}$ freeze-dried grape powder with $240 \mathrm{ml}$ of water two times a day) or the control group ( $46 \mathrm{~g}$ fructose, glucose, organic acids and fiber with $240 \mathrm{ml}$ of water two times a day). After a 3 week intervention period separated by 3 week washout periods, LDL particle size and concentrations of small LDL did not change in the study groups [81]. A prospective study evaluated the effectiveness of Bergamot supplementation for the treatment of dyslipidemic patients. A total 80 participants with moderate hypercholesterolemia received $150 \mathrm{mg} /$ day Bergavit $^{\circ}$ (Bergamot flavonoids containing $16 \%$ of neoeriocitrin, $47 \%$ of neohesperidin and 37\% of naringin) for 6 months. After 6 months, Bergavit ${ }^{\circ}$ supplementation significantly reduced sdLDL-3, - 4, and 5 particles compared to baseline [82]. In another study, 107 subjects with metabolic syndrome and NAFLD were given $1300 \mathrm{mg} / \mathrm{d}$ Bergamot polyphenolic fraction (BPF) in a capsule which contained flavonoids composed of $370 \mathrm{ppm}$ of neoeriocitrin, $520 \mathrm{ppm}$ of naringin, and $310 \mathrm{ppm}$ of neohesperidin. The results showed that sdLDL particles were significantly reduced after the 120 day intervention with BFP compared to baseline [83] (Table 3). Overall, in 6 out of 7 studies sdLDL was significantly reduced by fruit consumption, and in 2 out of 4 studies LDL particle size increased. In one study, in addition to the significant decrease in sdLDL, LDL particle number was also decreased.

\section{Nuts}

Nuts contain unsaturated fats, soluble fiber, antioxidants, and phytosterols that have potentially beneficial effects on serum lipids, blood pressure, and on inflammation [85]. A meta-analysis of clinical trials concluded that nut intake led to a significant beneficial effect on triglycerides, total cholesterol, LDL, and Apo B [86]. Furthermore, the findings of a previous systematic review showed that nuts especially almonds, pistachios, brazil nuts, peanuts, and hazelnuts may provide protection from oxidation LDL to due to the presence of bioactive antioxidant compounds in nuts. However, in some nuts such as walnuts due to their high content of unsaturated fatty acids this may increase the sensitivity to oxidation $[87,88]$. In a randomized crossover study, a pistachiosupplemented diet (50\% carbohydrates, 33\% fat, included $57 \mathrm{~g} /$ day of pistachios) and control diet (55\% carbohydrates, $30 \%$ fat) was administrated to 54 prediabetic patients for 2 weeks, with a 2-week washout period between interventions. The results showed that the small
LDL number was significantly decreased in the pistachio-supplemented diet compared to the control diet, whereas the LDL particle size did not differ between the groups [89]. Oliver Chen et al. conducted a randomized, crossover intervention, in which 45 patients with coronary artery disease were given a control diet without nuts (National Cholesterol Education Program (NCEP) diet) or an intervention diet of $85 \mathrm{~g}$ per day of almonds added to the NCEP diet for a 6 week period (each separated by a 4 week washout period). At the end of the study, no significant effect was observed on small density LDL-C levels following the consumption of almonds [90]. In a single-intervention study design, 21 healthy adults were given a hazelnut-enriched diet of 1 $\mathrm{g} / \mathrm{kg} /$ day of hazelnuts for 4 weeks. After 30 days, small LDL levels were significantly decreased compared with baseline [88]. In another study, 18 hyperlipidemic adults (13 postmenopausal women and 5 men), sequentially entered 4 stages of the interventional diet; 1) a habitual diet, 2) a habitual diet plus walnuts, 3) a low-fat diet, and 4) a low-fat diet plus walnuts. Each diet was undertaken for 4 to 6 weeks. At the end of the study, the results showed that all four diets did not affect LDL particle size; however, walnut supplementation ( $48 \mathrm{~g}$ walnuts/8460 kJ energy intake) led to a significant reduction in the distribution of cholesterol in the small LDL compared with a habitual diet [91]. In a randomized 4period crossover study, 48 overweight adults were randomized to four groups to consume $42.5 \mathrm{~g} / \mathrm{d}$ of almonds (ALD), $18 \mathrm{~g} / \mathrm{d}$ of cocoa powder and $43 \mathrm{~g} / \mathrm{d}$ of dark chocolate (CHOC), a combination of almonds, cocoa, and chocolate (CHOC+ALD), or an average American diet (AAD) as the control group. Each intervention was over a 4-week period with a 2-week washout periods between each. Results showed that, the concentration of sdLDL particles were significantly reduced in $(\mathrm{CHOC}+\mathrm{ALD})$ group compared with the control group (AAD), suggesting that the combination of almonds, cocoa, and chocolate could have a benefit to improve the risk of coronary heart disease [92]. In the PREDIMED trial, 169 diabetics, hyperlipidemic or hypertensive were randomly divided into those taking a Mediterranean diet (MeDiet) + extra-virgin olive oil (EVOO; $1 \mathrm{~L} /$ weekl) or MeDiet plus mixed nuts containing $15 \mathrm{~g}$ walnuts, $7.5 \mathrm{~g}$ hazelnuts and $7.5 \mathrm{~g}$ almonds, or control group who were advised on a low-fat diet, for 1 year. At the end of the study, compared with the baseline, MeDiet + nuts led to a significant reduction in medium-small LDL (10\%), very small LDL (11\%) and a significant rise in LDL size $(+0.2$ $\mathrm{nm})$. In addition, sdLDL particle levels decreased significantly in the MeDiet + nuts group compared with the control group, and the increase in the LDL size change was statistically significant compared to the other groups [93]. In a three-period, cross-over study, 28 healthy 


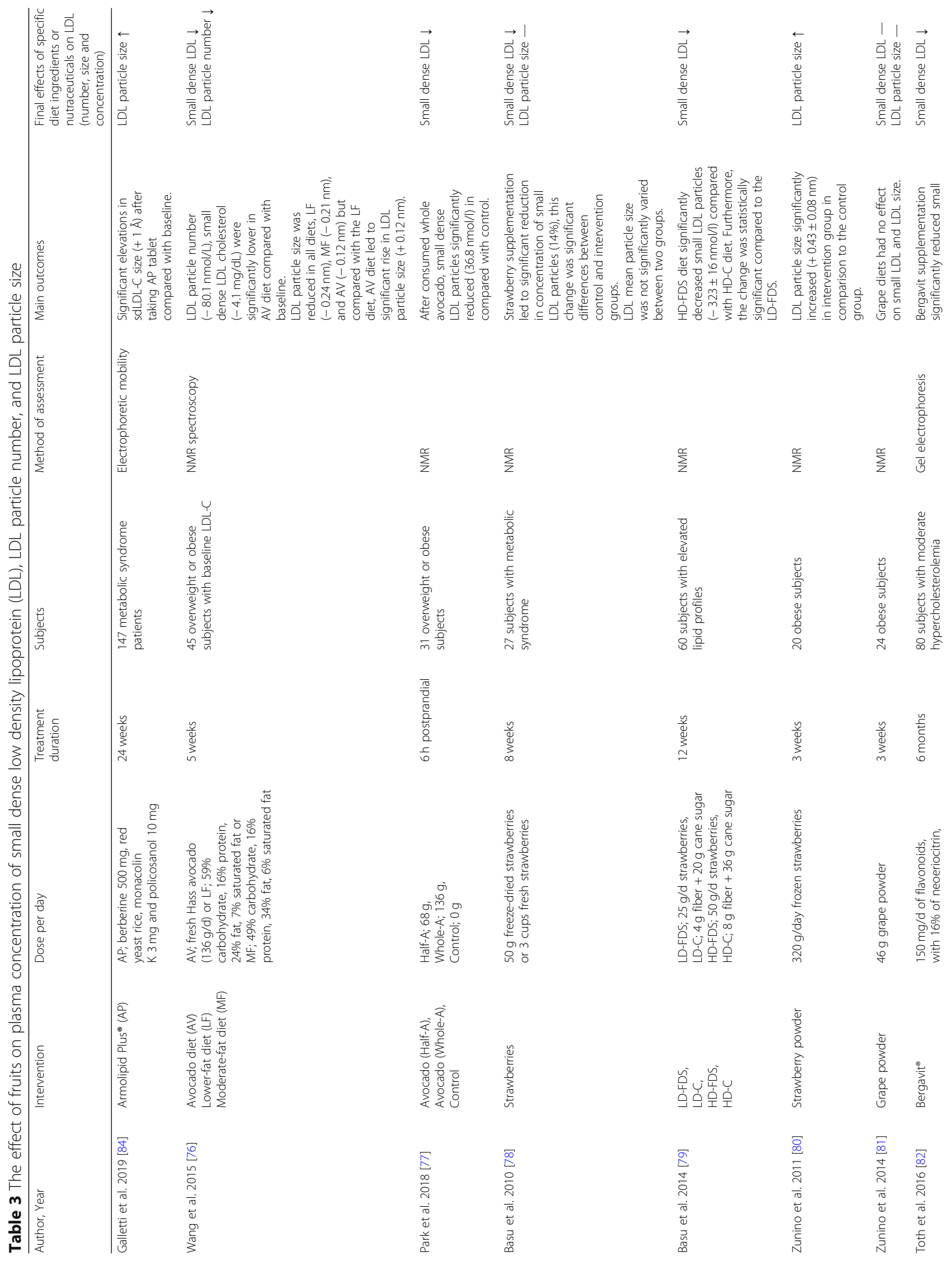




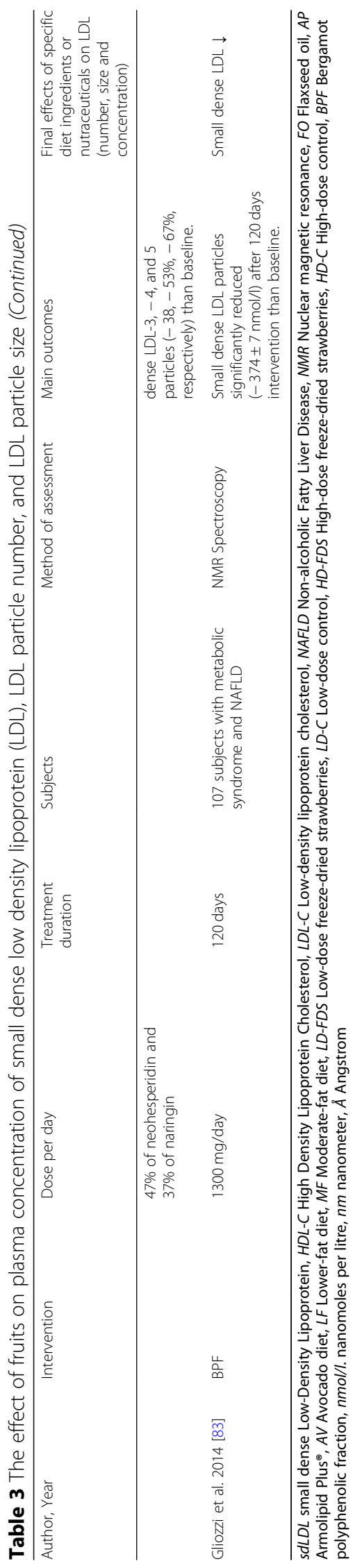




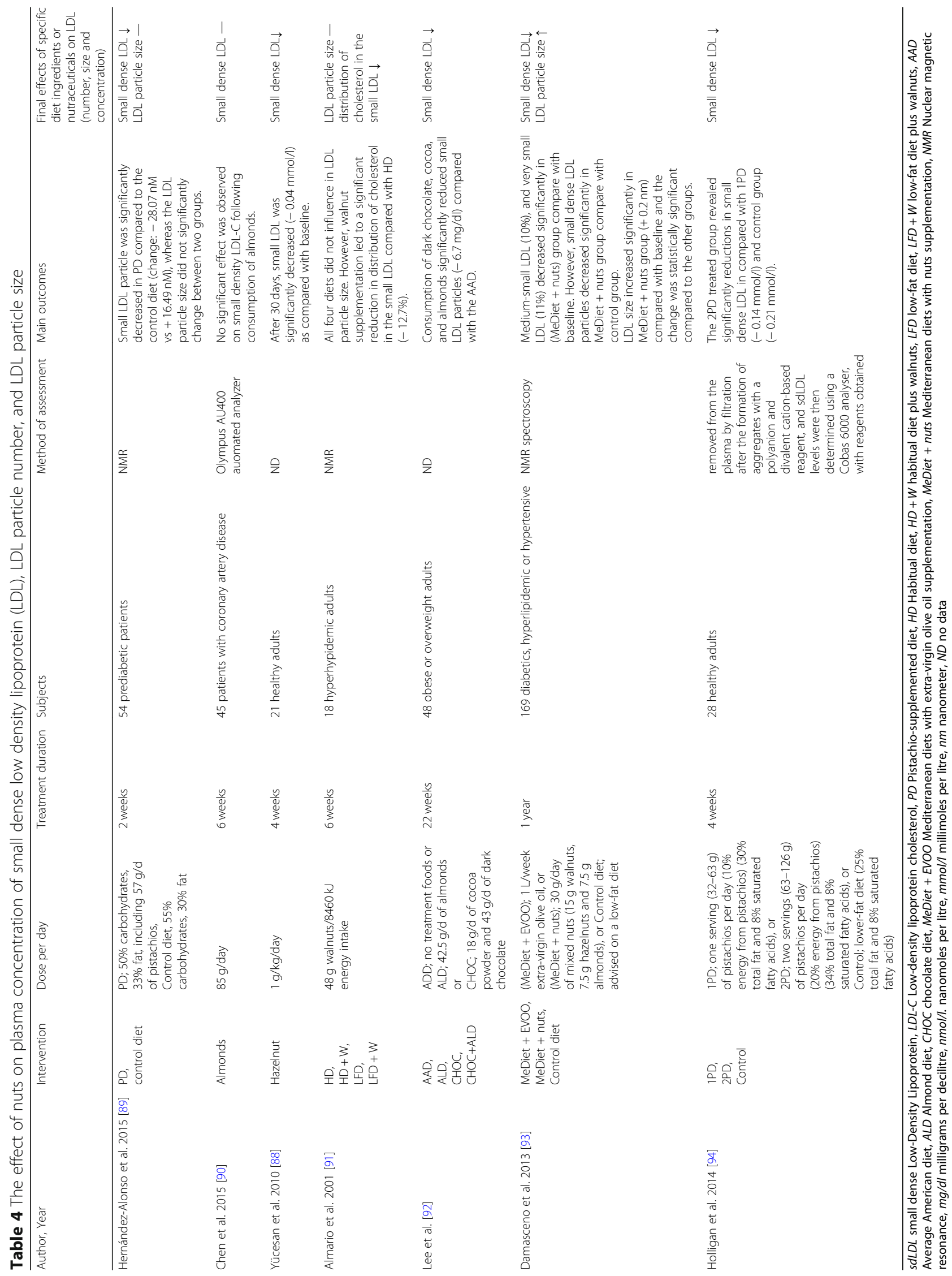


adults were assigned into three groups of; a 1 serving of pistachio per day (1 PD) diet that contained 30\% energy from total fat (TF), $8 \%$ from SFA, and 10\% from pistachios (one serving of pistachios/d or 32-63 g/d), a 2PD diet that contained 34\% energy from TF, $8 \%$ from SFA, and $20 \%$ from pistachios (two serving of pistachios/d or $63-126 \mathrm{~g} / \mathrm{d}$ ), or a control diet that contained $25 \%$ energy from TF and $8 \%$ from SFA (lower-fat diet). Each of the diets was conducted over a 4-week period with a 2-week washout period between the diets. The results showed that the 2PD treated group had a significant reduction in sdLDL in compared to both the 1PD and control groups [94] (Table 4). Overall, in 5 out of 6 studies consumption of nuts significantly reduced sdLDL. LDL particle size was increased in 1 out of 3 studies, in 1 study the distribution of cholesterol in the small LDL was decreased.

\section{Curcumin}

Curcumin is an active ingredient of turmeric spices (Curcuma longa L.) and has been used as a food spice and herbal remedy for centuries in different traditional medicine systems [95]. Because of its highly bioactive compounds it has been reported to have several pharmacological effects including anti-inflammatory, antitumor, lipid-modifying, antioxidant, anti-steatotic, antifibrotic, cardioprotective and antithrombotic activities [96-105]. The anti-atherosclerotic and cardioprotective effects are thought to be mediated through reduced LDL-oxidation [106, 107]. In a recent report, 117 metabolic syndrome patients were asked to consume 1000 $\mathrm{mg} /$ day curcuminoids plus $5 \mathrm{mg}$ piperine (intervention group) or $5 \mathrm{mg}$ piperine as the comparative control for 8 weeks. At the end of the study, sdLDL levels significantly decreased in the intervention group compared with baseline and between the two groups [97]. In a randomized crossover study, 30 obese participants with hyperlipidemia who were treatment naïve were randomized into either the curcuminoids group (1000 $\mathrm{mg} /$ day $+5 \mathrm{mg}$ piperine) or the placebo group (5 $\mathrm{mg}$ piperine) for a 4-week period, with a 2-week washout period and then crossed over for a further 4 week period. At the end of the trial, no significant change in sdLDL concentrations were observed after taking the curcumin supplement compared with placebo [108] (Table 5). In 2 studies reviewed here sdLDL was decreased in 1 study after supplementation with curcumin.

\section{Other nutraceuticals}

\section{Oolong tea}

Oolong tea is partially fermented tea extracted from the leaves of Camellia sinensis, and contains high levels of polyphenolic compounds. It has been shown to improve the lipid profile especially effective in lowering cholesterol $[109,110]$. In one clinical trial study, 12 patients with previous myocardial infarction and 10 patients with stable angina pectoris were divided into two groups and asked to drink $1000 \mathrm{ml} /$ day (two bags of tea) oolong tea, or water as a control group for 4 weeks. At the endo of the study, a significant increase in plasma LDL particle size was observed in the oolong tea group compared with baseline [111].

\section{Brown rice}

Brown rice, as whole grain rice, is nutrient-rich including fiber, phytic acids, vitamins B and E, $\alpha$-tocopherol, $\gamma$ -oryzanol and $\gamma$-amino butyric acid (GABA) [112]. In a randomized controlled trial, 42 prediabetic, overweight patients were randomly assigned into $400 \mathrm{~g}$ partiallyabraded brown rice (PABR) or white rice (WR) daily for 12 weeks. The results showed that particle numbers of small LDL and very small LDL were significantly reduced in the PABR group, whereas in the WR group, they were increased [113].

\section{Chitosan}

Chitosan is derived from chitin deacetylation and extracted from shellfish. It has anti-fungal, antibacterial, antioxidant activity and reduced fat absorption properties [114-116]. Several meta-analyses studies in patients with hypercholesterolemia [117] showed that chitosan only reduced total cholesterol In a pilot study, 28 patients with hypertriglyceridemia received 2 tablets daily $(125 \mathrm{mg} / \mathrm{d})$ of chitosan derived from fungal mycelium for 4 months. The results showed that LDL peak particle size and LDL subclasses did not differ between groups though the LDL-2 subclass was significantly increased after 4 months supplementation [118].

\section{L-citrulline}

L-citrulline is non-essential amino acid that found in abundance in watermelon. Potential beneficial effects on cardio-metabolic health $[119,120]$ have been reported. In a recent study, 22 patients with flow mediated dilation of the brachial artery $(<5.5 \%)$ were recruited take $800 \mathrm{mg} /$ day of L-citrulline for 8 weeks. The results showed that L-citrulline supplementation had no effect on sdLDL levels [121].

\section{Armolipid plus ${ }^{\oplus}$}

Armolipid Plus ${ }^{\circ}$ tablets contain $200 \mathrm{mg}$ of RYR (3 mg of monacolin $\mathrm{K}$ with citrinine and aflatoxins free), $500 \mathrm{mg}$ of berberine, $10 \mathrm{mg}$ of policosanols, $0.2 \mathrm{mg}$ of folic acid, $2.0 \mathrm{mg}$ of coenzyme Q10 and $0.5 \mathrm{mg}$ of astaxanthin. In a comparative study, 30 patients with familial combined hyperlipidemia undertook a run-in period of 4 weeks of 


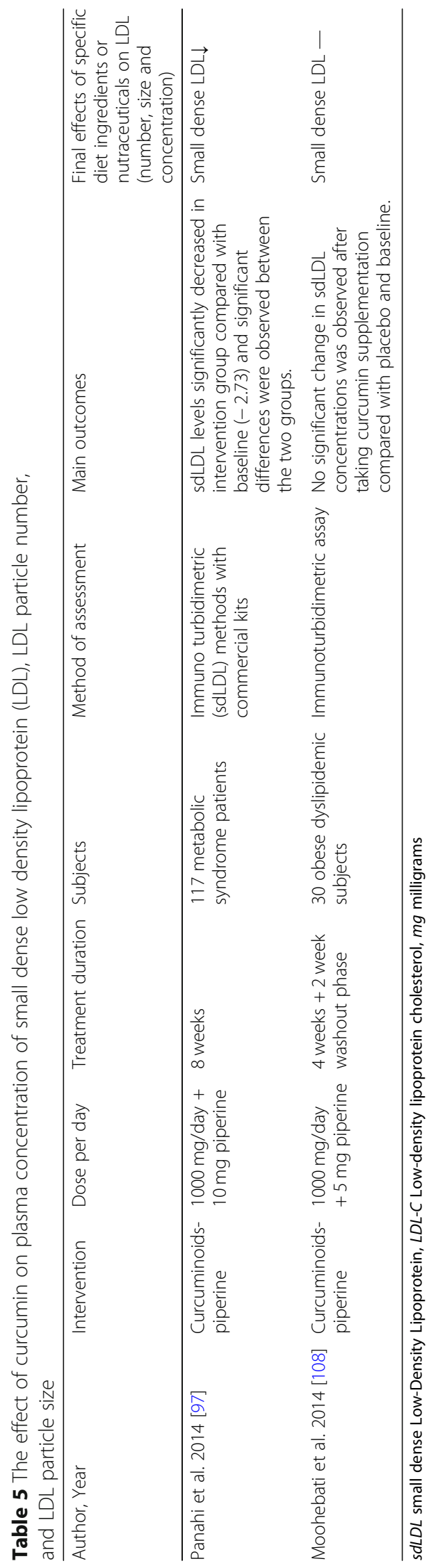




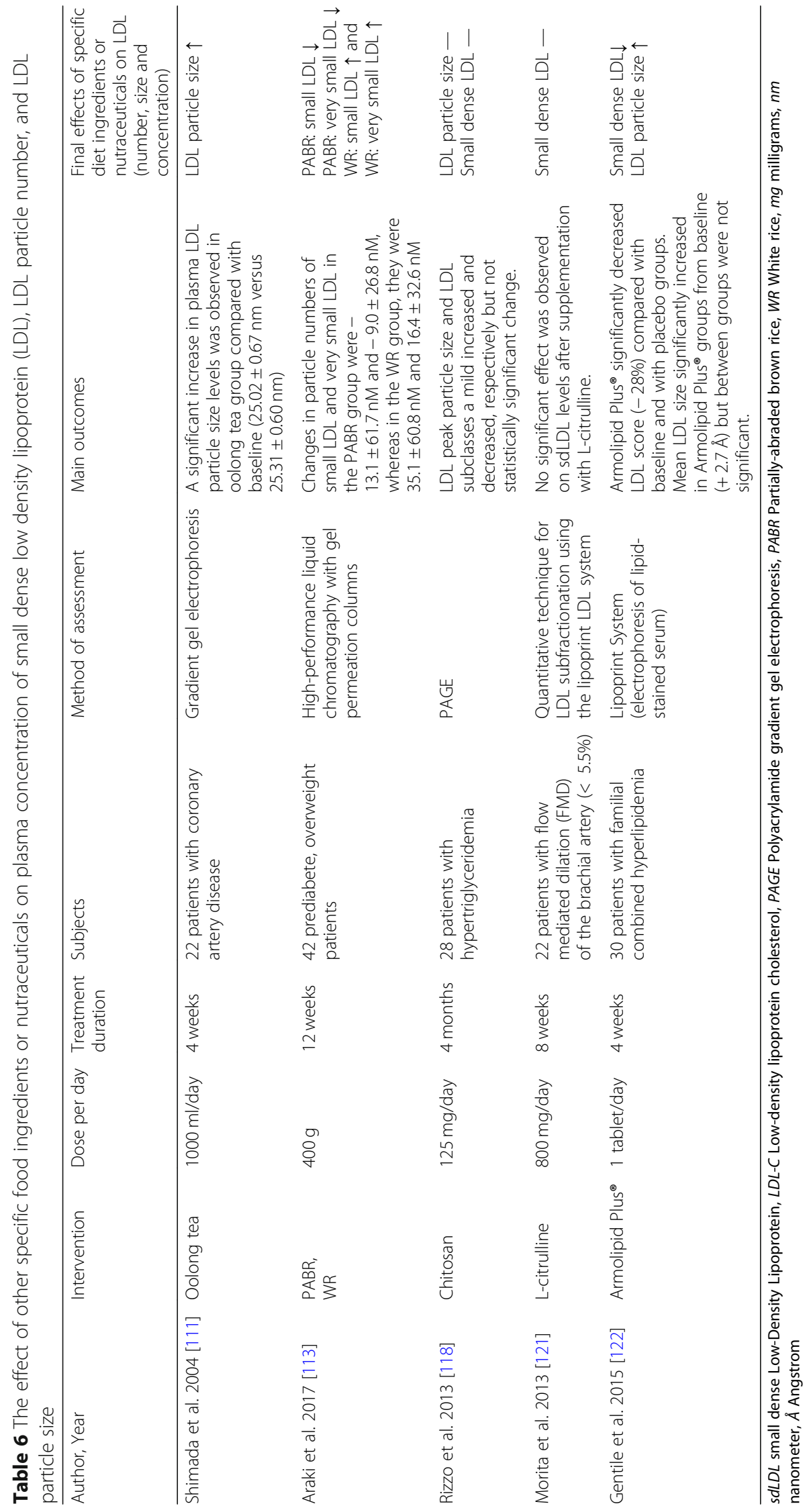


a normocaloric diet (54\% carbohydrate, $16 \%$ protein, $30 \%$ fat, $45-55 \mathrm{~g} /$ day fiber), following which they were randomized to Armolipid Plus ${ }^{\bullet}$ (one tablet per day) or placebo (microcrystalline cellulose, iron oxide brown 70 , Compritol E ATO and magnesium stearate with the same shape and taste) groups for 8 weeks. The results showed that Armolipid Plus ${ }^{\circ}$ significantly decreased the LDL score compared with baseline and with the placebo group. Whilst mean LDL size significantly increased in the Armolipid Plus ${ }^{\oplus}$ group from baseline, there was no difference compared to placebo [122]. In another placebo-controlled trial, 147 individuals with metabolic syndrome were randomized into two groups, the intervention group received one tablet daily of Armolipid Plus $^{\circ}$ whilst the control group received a placebo tablet (microcrystalline cellulose, iron oxide brown) for 24 weeks. The results showed that patients who received Armolipid Plus ${ }^{\bullet}$ had significantly larger sdLDL-C sizes in comparison to baseline, though the differences between groups were not significant [84] (Table 6).

\section{Conclusion}

This review has comprehensively assessed the effects of nutraceuticals and other diet ingredients on sdLDL, LDL particle number, and LDL particle size in human clinical trials. The results have shown that almost all of the nutraceuticals and specific diet ingredients discussed above such as omega- 3 fatty acids have beneficial effects of LDL variants (Tables 1, 2, 3, 4, 5, and 6). Most of these agents including olive oil, phytosterols, psyllium, fish oil, EPA, DHA, flaxseed oil, berberine, avocado, strawberry, nuts (including pistachio, almonds and hazelnuts), curcumin and olong tea reduced sdLDL levels, LDL particle numbers or increased LDL particle size (Fig. 2). However, for many of the agents there are currently very few studies and the trials undertaken were

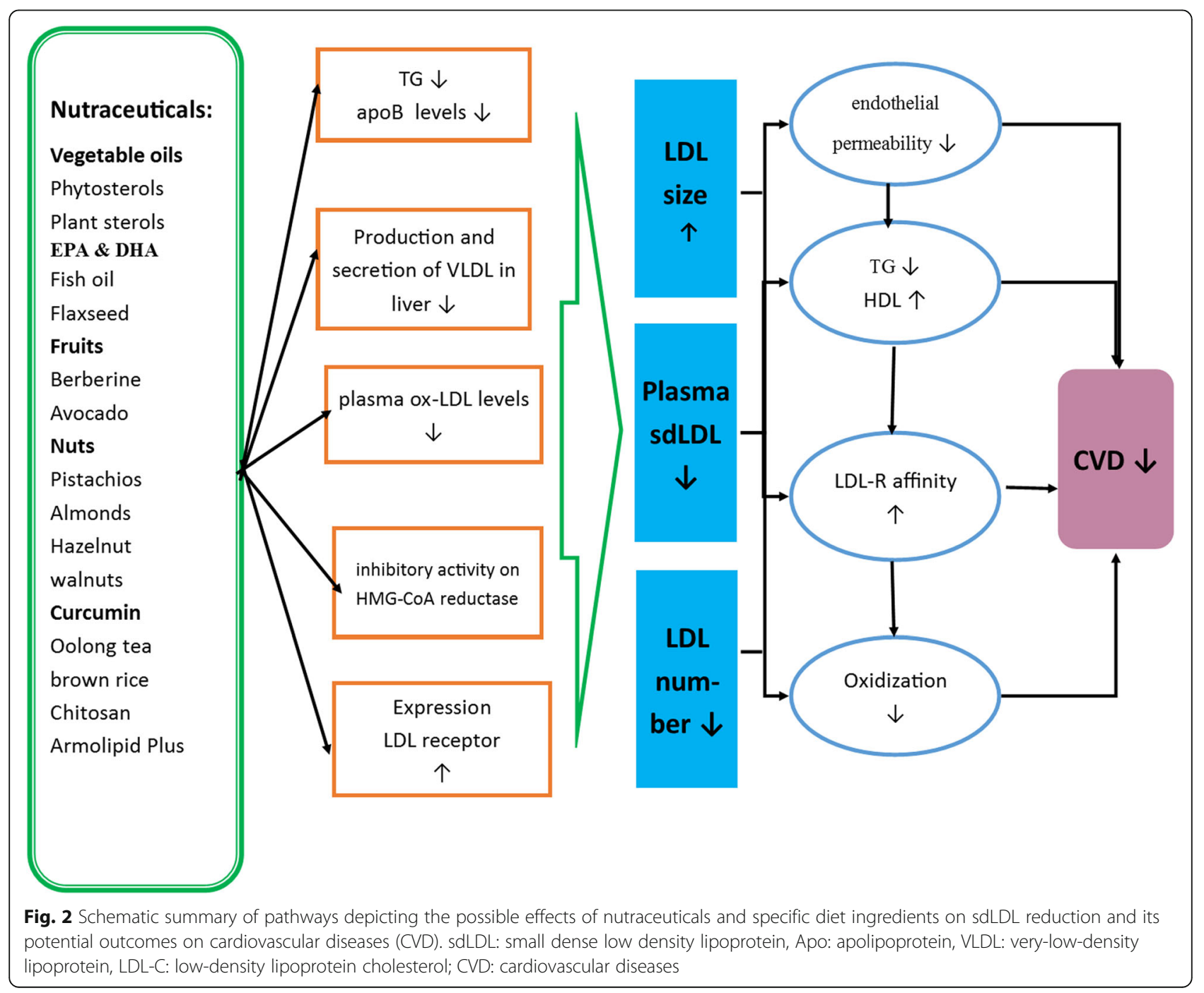


often limited by study number, duration of the intervention or their design with few randomized clinical controlled trials. It has been reported that smaller and denser LDL particles have a higher susceptibility to oxidation and they are an independent atherogenic risk factor for CVD; therefore, larger clinical trials with plantderived therapeutic agents and omega- 3 fatty acids, or other specific ingredients of foods, are required to clarify and confirm their efficacy to lower the levels of sdLDL, LDL particle numbers or increase LDL particle size, and to determine optimal dosing strategies. However, this review does highlight that medicinal plants, nutraceuticals and omega- 3 fatty acids may have a role as natural products that can be used as adjunct or complementary therapeutic agents to reduce sdLDL levels, LDL particle numbers or increase LDL particle size that may have a beneficial impact on CVD risk.

However, it should be noted that the included studies in this review did not assess whether improvement in sdLDL levels led to a clinical impact. In addition, measurement methods of sdLDL levels differed between studies and the results may not be directly comparable. Thus, it is recommended that future research focusing on the evaluation of the efficacy of food ingredients or nutraceuticals in populations with high sdLDL levels should be of sufficient power and of robust design to give definitive conclusions, and to determine sdLDL using standardized methodology.

\begin{abstract}
Abbreviations
CVDs: Cardiovascular diseases; LDL-C: low density lipoprotein cholesterol; sdLDL: small dense low-dense lipoprotein; HDL: High-density lipoproteins; IbLDL: Large buoyant; VLDL: Very low-density lipoproteins; CETP: Cholesteryl ester transfers protein; LPL: Lipoprotein lipase; HL: Hepatic lipase; IDL: Intermediate-density lipoprotein; IHD: Ischemic heart disease; CHD: Coronary heart disease; AACE: Association of Clinical Endocrinologists; MUFA: Monounsaturated fatty acids; PAGE: Polyacrylamide gradient gel electrophoresis; PABR: Partially-abraded brown rice; WR: White rice; EPA: Eicosapentaenoic acid; SB: Sucrose-sweetened beverage; LPCOO: Lowpolyphenol-content olive oil; HPCOO: High-polyphenol-content olive oil; IEB: Nositol-enriched beverage; NMR: Nuclear magnetic resonance; FCHL: Familial combined hyperlipidemia; SBO: Soybean oil; RBO: Rice bran oil; MeDiet: Mediterranean diet; ALA: Alpha-linolenic acid; TG: Triglycerides; DHA: Docosahexaenoic acid; NAFLD: Non-alcoholic Fatty Liver Disease; VAPII: Vertical Auto Profile II; ALM: Almonds; CHOC: Dark chocolate; EVOO: Extravirgin olive oil; FMD: Flow mediated dilation
\end{abstract}

\section{Acknowledgements}

None.

\section{Authors' contributions}

$\mathrm{AS}$ and $\mathrm{MB}$ conceived the topic and designed the manuscript. ST and MB performed literature search and prepared the first draft. SLA, GA, HMO and AS reviewed and revised the manuscript. All authors approved the final version.

\section{Funding}

None.

Availability of data and materials

Not applicable.
Ethics approval and consent to participate

Not applicable.

\section{Consent for publication}

Not applicable.

\section{Competing interests}

The authors declare that they have no competing interests.

\section{Author details}

'Students' Research Committee, Isfahan University of Medical Sciences, Isfahan, Iran. ${ }^{2}$ Department of Community Nutrition, School of Nutrition and Food Science, Food Security Research Center, Isfahan University of Medical Sciences, Isfahan, Iran. ${ }^{3}$ Weill Cornell Medicine Qatar, Doha, Qatar. ${ }^{4}$ Food Security Research Center and Department of Community Nutrition, School of Nutrition and Food Science, Isfahan University of Medical Sciences, Isfahan, Iran. ${ }^{5}$ Department of Pharmaceutics, Faculty of Pharmacy, Al-Zahraa University, Karbala, Iraq. ${ }^{6} \mathrm{Halal}$ Research Center of IRI, FDA, Tehran, Iran. ${ }^{7}$ Biotechnology Research Center, Pharmaceutical Technology Institute, Mashhad University of Medical Sciences, Mashhad, Iran. ${ }^{8}$ Neurogenic Inflammation Research Center, Mashhad University of Medical Sciences, Mashhad, Iran.

Received: 18 October 2019 Accepted: 31 March 2020

Published online: 11 April 2020

\section{References}

1. Dhungana RR, Thapa P, Devkota S, Banik PC, Gurung Y, Mumu SJ, Shayami A, Ali L. Prevalence of cardiovascular disease risk factors: a communitybased cross-sectional study in a peri-urban community of Kathmandu, Nepal. Indian Heart J. 2018;70:S20-7.

2. Benjamin EJ, Muntner P, Alonso A, Bittencourt MS, Callaway CW, Carson AP, Chamberlain AM, Chang AR, Cheng S, Das SR, et al. Heart disease and stroke Statistics-2019 update: a report from the American Heart Association. Circulation. 2019;139:e56-e528.

3. Pletcher MJ, Moran AE. Cardiovascular Risk Assessment. Med Clin North Am. 2017;101:673-88.

4. Ariyanti R, Besral B. Dyslipidemia associated with hypertension increases the risks for coronary heart disease: a case-control study in Harapan Kita hospital, National Cardiovascular Center. Jakarta J Lipids. 2019;2019:2517013.

5. Ivanova EA, Myasoedova VA, Melnichenko AA, Grechko AV, Orekhov AN. Small dense low-density lipoprotein as biomarker for atherosclerotic diseases. Oxidative Med Cell Longev. 2017;2017:1273042.

6. Austin MA, Breslow JL, Hennekens CH, Buring JE, Willett WC, Krauss RM. Low-density lipoprotein subclass patterns and risk of myocardial infarction. JAMA. 1988;260:1917-21.

7. Yee MS, Pavitt DV, Tan T, Venkatesan S, Godsland IF, Richmond W, Johnston DG. Lipoprotein separation in a novel iodixanol density gradient, for composition, density, and phenotype analysis. J Lipid Res. 2008;49:1364-71.

8. Witte DR, Taskinen MR, Perttunen-Nio H, Van Tol A, Livingstone S, Colhoun HM. Study of agreement between LDL size as measured by nuclear magnetic resonance and gradient gel electrophoresis. J Lipid Res. 2004;45: 1069-76.

9. Hoefner DM, Hodel SD, O'Brien JF, Branum EL, Sun D, Meissner I, McConnell JP. Development of a rapid, quantitative method for LDL subfractionation with use of the Quantimetrix Lipoprint LDL system. Clin Chem. 2001;47:266-74.

10. Jellinger $P$, Smith D, Mehta A, Ganda O, Handelsman $Y$, Rodbard $H$, Shepherd M, Seibel J. American Association of Clinical Endocrinologists' guidelines for management of dyslipidemia and prevention of atherosclerosis. Endocr Pract. 2012;18:1-78.

11. Ohmura H, Mokuno H, Sawano M, Hatsumi C, Mitsugi Y, Watanabe Y, Daida $\mathrm{H}$, Yamaguchi H. Lipid compositional differences of small, dense low-density lipoprotein particle influence its oxidative susceptibility: possible implication of increased risk of coronary artery disease in subjects with phenotype B. Metabolism. 2002;51:1081-7.

12. Hirayama S, Miida T. Small dense LDL: an emerging risk factor for cardiovascular disease. Clin Chim Acta. 2012;414:215-24.

13. Toft-Petersen AP, Tilsted HH, Aarøe J, Rasmussen K, Christensen T, Griffin BA, Aardestrup IV, Andreasen A, Schmidt EB. Small dense LDL particles-a 
predictor of coronary artery disease evaluated by invasive and CT-based techniques: a case-control study. Lipids Health Dis. 2011;10:21.

14. Ai M, Otokozawa S, Asztalos BF, Ito Y, Nakajima K, White CC, Cupples LA, Wilson PW, Schaefer EJ. Small dense LDL cholesterol and coronary heart disease: results from the Framingham offspring study. Clin Chem. 2010;56: 967-76.

15. Fan J, Liu Y, Yin S, Chen N, Bai X, Ke Q, Shen J, Xia M. Small dense LDL cholesterol is associated with metabolic syndrome traits independently of obesity and inflammation. Nutr Metab. 2019;16:7.

16. Lamarche B, Tchernof A, Mauriege P, Cantin B, Dagenais GR, Lupien PJ, Despres JP. Fasting insulin and apolipoprotein B levels and low-density lipoprotein particle size as risk factors for ischemic heart disease. JAMA. 1998;279:1955-61.

17. Linton MF, Yancey PG, Davies SS, Jerome WG, Linton EF, Song WL, Doran AC, Vickers KC. The role of lipids and lipoproteins in atherosclerosis. South Dartmouth: In: Endotext: MDText. com, Inc.; 2019.

18. National Cholesterol Education Program (NCEP) Expert Panel on Detection, Evaluation, and Treatment of High Blood Cholesterol in Adults (Adult Treatment Panel III). Third report of the National Cholesterol Education Program (NCEP) Expert Panel on Detection, Evaluation, and Treatment of High Blood Cholesterol in Adults (Adult Treatment Panel III) final report. Circulation. 2002;106:3143-421.

19. Ellsworth D, Costantino N, Blackburn H, Engler R, Kashani M, Vernalis M. Lifestyle modification interventions differing in intensity and dietary stringency improve insulin resistance through changes in lipoprotein profiles. Obes Sci Pract. 2016;2:282-92.

20. Chiuve SE, Cook NR, Shay CM, Rexrode KM, Albert CM, Manson JE, Willett WC, Rimm EB. Lifestyle-based prediction model for the prevention of CVD: the healthy heart score. J Am Heart Assoc. 2014;3:e000954.

21. Mannu GS, Zaman MJ, Gupta A, Rehman HU, Myint PK. Evidence of lifestyle modification in the management of hypercholesterolemia. Curr Cardiol Rev. 2013;9:2-14.

22. Alissa EM, Ferns GA. Functional foods and nutraceuticals in the primary prevention of cardiovascular diseases. J Nutr Metab. 2012;2012:569486.

23. Ramaa C, Shirode A, Mundada A, Kadam V. Nutraceuticals-an emerging era in the treatment and prevention of cardiovascular diseases. Curr Pharm Biotechnol. 2006;7:15-23.

24. Zuchi C, Ambrosio G, Luscher TF, Landmesser U. Nutraceuticals in cardiovascular prevention: lessons from studies on endothelial function. Cardiovasc Ther. 2010;28:187-201.

25. Badimon L, Vilahur G, Padro T. Nutraceuticals and atherosclerosis: human trials. Cardiovasc Ther. 2010;28:202-15.

26. McCarty MF. Nutraceutical resources for diabetes prevention--an update. Med Hypotheses. 2005;64:151-8.

27. Davi G, Santilli F, Patrono C. Nutraceuticals in diabetes and metabolic syndrome. Cardiovasc Ther. 2010;28:216-26.

28. Bagherniya M, Nobili V, Blesso CN, Sahebkar A. Medicinal plants and bioactive natural compounds in the treatment of non-alcoholic fatty liver disease: a clinical review. Pharmacol Res. 2018;130:213-40.

29. Izzo R, de Simone G, Giudice R, Chinali M, Trimarco V, De Luca N, Trimarco B. Effects of nutraceuticals on prevalence of metabolic syndrome and on calculated Framingham risk score in individuals with dyslipidemia. J Hypertens. 2010;28:1482-7.

30. Houston M. The role of nutraceutical supplements in the treatment of dyslipidemia. J Clin Hypertens (Greenwich). 2012;14:121-32.

31. Scicchitano P, Cameli M, Maiello M, Modesti PA, Muiesan ML, Novo S, Palmiero P, Saba PS, Pedrinelli R, Ciccone MM. Nutraceuticals and dyslipidaemia: beyond the common therapeutics. J Funct Foods. 2014;6: $11-32$.

32. Mannarino MR, Ministrini S, Pirro M. Nutraceuticals for the treatment of hypercholesterolemia. Eur J Intern Med. 2014;25:592-9.

33. Cicero AF, Colletti A, Bajraktari G, Descamps O, Djuric DM, Ezhov M, Fras Z, Katsiki N, Langlois M, Latkovskis G. Lipid-lowering nutraceuticals in clinical practice: position paper from an international lipid expert panel. Nutr Rev. 2017;75:731-67.

34. Patti AM, Al-Rasadi K, Giglio RV, Nikolic D, Mannina C, Castellino G, Chianetta R, Banach M, Cicero AF, Lippi G. Natural approaches in metabolic syndrome management. Arch Med Sci. 2018;14:422.

35. Sahebkar A, Serban M-C, Gluba-Brzozka A, Mikhailidis DP, Cicero AF, Rysz J, Banach M. Lipid-modifying effects of nutraceuticals: an evidence-based approach. Nutrition. 2016:32:1179-92.
36. Choudhary SP, Tran LS. Phytosterols: perspectives in human nutrition and clinical therapy. Curr Med Chem. 2011;18:4557-67.

37. Chen Q, Gruber H, Swist E, Coville K, Pakenham C, Ratnayake WM, Scoggan KA. Dietary phytosterols and phytostanols decrease cholesterol levels but increase blood pressure in WKY inbred rats in the absence of salt-loading. Nutr Metab (Lond). 2010;7:11.

38. Awad A, Downie A, Fink C, Kim U. Dietary phytosterol inhibits the growth and metastasis of MDA-MB-231 human breast cancer cells grown in SCID mice. Anticancer Res. 2000;20:821-4.

39. Hernández-Mijares A, Bañuls C, Jover A, Solá E, Bellod L, MartínezTriguero ML, Lagarda MJ, Víctor VM, Rocha M. Low intestinal cholesterol absorption is associated with a reduced efficacy of phytosterol esters as hypolipemic agents in patients with metabolic syndrome. Clin Nutr. 2011;30:604-9.

40. Moruisi KG, Oosthuizen W, Opperman AM. Phytosterols/stanols lower cholesterol concentrations in familial hypercholesterolemic subjects: a systematic review with meta-analysis. J Am Coll Nutr. 2006;25:41-8.

41. Wu T, Fu J, Yang Y-X, Zhang L-S, Han J-H. The effects of phytosterols/stanols on blood lipid profiles: a systematic review with meta-analysis. Asia Pac J Clin Nutr. 2009;18:179-86.

42. Bañuls C, Rovira-Llopis S, Falcón R, Veses S, Monzó N, Víctor VM, Rocha M, Hernández-Mijares A. Chronic consumption of an inositol-enriched carob extract improves postprandial glycaemia and insulin sensitivity in healthy subjects: a randomized controlled trial. Clin Nutr. 2016;35:600-7.

43. Hernáez Á, Remaley AT, Farràs M, Fernández-Castillejo S, Subirana I, Schröder H, Fernández-Mampel M, Muñoz-Aguayo D, Sampson M, Solà R. Olive oil polyphenols decrease LDL concentrations and LDL atherogenicity in men in a randomized controlled trial. J Nutr. 2015;145:1692-7.

44. Sialvera T, Pounis G, Koutelidakis A, Richter D, Yfanti G, Kapsokefalou M, Goumas G, Chiotinis N, Diamantopoulos E, Zampelas A. Phytosterols supplementation decreases plasma small and dense LDL levels in metabolic syndrome patients on a westernized type diet. Nutr Metab Cardiovasc Dis. 2012;22:843-8.

45. Garoufi A, Vorre S, Soldatou A, Tsentidis C, Kossiva L, Drakatos A, Marmarinos A, Gourgiotis D. Plant sterols-enriched diet decreases small, dense LDL-cholesterol levels in children with hypercholesterolemia: a prospective study. Ital J Pediatr. 2014;40:42.

46. Kratz M, Gülbahçe E, von Eckardstein A, Cullen P, Cignarella A, Assmann G Wahrburg U. Dietary mono-and polyunsaturated fatty acids similarly affect LDL size in healthy men and women. J Nutr. 2002;132:715-8.

47. Shrestha S, Freake HC, MCGrane MM, Volek JS, Fernandez ML. A combination of psyllium and plant sterols alters lipoprotein metabolism in hypercholesterolemic subjects by modifying the intravascular processing of lipoproteins and increasing LDL uptake. J Nutr. 2007;137: 1165-70.

48. Shrestha S, Volek JS, Udani J, Wood RJ, Greene CM, Aggarwal D, Contois JH, Kavoussi B, Fernandez ML. A combination therapy including psyllium and plant sterols lowers LDL cholesterol by modifying lipoprotein metabolism in hypercholesterolemic individuals. J Nutr. 2006;136:2492-7.

49. Earnest CP, Mikus CR, Lemieux I, Arsenault BJ, Church TS. Examination of encapsulated phytosterol ester supplementation on lipid indices associated with cardiovascular disease. Nutrition. 2007;23:625-33.

50. Matvienko OA, Lewis DS, Swanson M, Arndt B, Rainwater DL, Stewart J, Alekel DL. A single daily dose of soybean phytosterols in ground beef decreases serum total cholesterol and LDL cholesterol in young, mildly hypercholesterolemic men. Am J Clin Nutr. 2002;76:57-64.

51. Theuwissen E, Plat J, van der Kallen CJ, van Greevenbroek MM, Mensink RP. Plant stanol supplementation decreases serum triacylglycerols in subjects with overt hypertriglyceridemia. Lipids. 2009:44:1131-40.

52. Utarwuthipong T, Komindr S, Pakpeankitvatana V, Songchitsomboon S, Thongmuang N. Small dense low-density lipoprotein concentration and oxidative susceptibility changes after consumption of soybean oil, rice bran oil, palm oil and mixed rice bran/palm oil in hypercholesterolaemic women. J Int Med Res. 2009;37:96-104.

53. Ciccone MM, Scicchitano P, Gesualdo M, Zito A, Carbonara S, Ricci G, Cortese F, Giordano P. The role of omega-3 polyunsaturated fatty acids supplementation in childhood: a review. Recent Pat Cardiovasc Drug Discov. 2013;8:42-55.

54. Parker HM, Johnson NA, Burdon CA, Cohn JS, O'Connor HT, George J. Omega-3 supplementation and non-alcoholic fatty liver disease: a systematic review and meta-analysis. J Hepatol. 2012;56:944-51. 
55. Chen C, Yu X, Shao S. Effects of omega-3 fatty acid supplementation on glucose control and lipid levels in type 2 diabetes: a meta-analysis. PLoS One. 2015;10:e0139565.

56. Djoussé L, Akinkuolie AO, Wu JH, Ding EL, Gaziano JM. Fish consumption, omega-3 fatty acids and risk of heart failure: a meta-analysis. Clin Nutr. 2012; 31:846-53.

57. Kwak SM, Myung S-K, Lee YJ, Seo HG, Group KM-aS. Efficacy of omega-3 fatty acid supplements (eicosapentaenoic acid and docosahexaenoic acid) in the secondary prevention of cardiovascular disease: a meta-analysis of randomized, double-blind, placebo-controlled trials. Arch Intern Med. 2012; 172:686-94.

58. Piolot A, Blache D, Boulet L, Fortin LJ, Dubreuil D, Marcoux C, Davignon J, Lussier-Cacan S. Effect of fish oil on LDL oxidation and plasma homocysteine concentrations in health. J Lab Clin Med. 2003;141:41-9.

59. Mori TA. Effect of fish and fish oil-derived omega-3 fatty acids on lipid oxidation. Redox Rep. 2004;9:193-7.

60. Higgins S, Carroll YL, McCarthy SN, Corridan BM, Roche HM, Wallace JM, O'Brien NM, Morrissey PA. Susceptibility of LDL to oxidative modification in healthy volunteers supplemented with low doses of $\mathrm{n}-3$ polyunsaturated fatty acids. Br J Nutr. 2001;85:23-31.

61. Ouellette C, Rudkowska I, Lemieux S, Lamarche B, Couture P, Vohl M-C. Gene-diet interactions with polymorphisms of the MGLL gene on plasma low-density lipoprotein cholesterol and size following an omega-3 polyunsaturated fatty acid supplementation: a clinical trial. Lipids Health Dis. 2014;13:86.

62. Oelrich B, Dewell A, Gardner C. Effect of fish oil supplementation on serum triglycerides, LDL cholesterol and LDL subfractions in hypertriglyceridemic adults. Nutr Metab Cardiovasc Dis. 2013;23:350-7.

63. Petersen M, Pedersen H, Major-Pedersen A, Jensen T, Marckmann P. Effect of fish oil versus corn oil supplementation on LDL and HDL subclasses in type 2 diabetic patients. Diabetes Care. 2002;25:1704-8.

64. Suzukawa M, Abbey M, Howe PR, Nestel PJ. Effects of fish oil fatty acids on low density lipoprotein size, oxidizability, and uptake by macrophages. J Lipid Res. 1995;36:473-84.

65. Asztalos IB, Gleason JA, Sever S, Gedik R, Asztalos BF, Horvath KV, Dansinger ML, Lamon-Fava S, Schaefer EJ. Effects of eicosapentaenoic acid and docosahexaenoic acid on cardiovascular disease risk factors: a randomized clinical trial. Metabolism. 2016;65:1636-45.

66. Satoh N, Shimatsu A, Kotani K, Sakane N, Yamada K, Suganami T, Kuzuya H, Ogawa Y. Purified eicosapentaenoic acid reduces small dense LDL, remnant lipoprotein particles, and C-reactive protein in metabolic syndrome. Diabetes Care. 2007:30:144-6.

67. Mori TA, Burke V, Puddey IB, Watts GF, O'Neal DN, Best JD, Beilin LJ. Purified eicosapentaenoic and docosahexaenoic acids have differential effects on serum lipids and lipoproteins, LDL particle size, glucose, and insulin in mildly hyperlipidemic men. Am J Clin Nutr. 2000;71:1085-94.

68. Kelley DS, Siegel D, Vemuri M, Mackey BE. Docosahexaenoic acid supplementation improves fasting and postprandial lipid profiles in hypertriglyceridemic men. Am J Clin Nutr. 2007;86:324-33.

69. Maki KC, Van Elswyk ME, McCarthy D, Hess SP, Veith PE, Bell M, Subbaiah P, Davidson $\mathrm{MH}$. Lipid responses to a dietary docosahexaenoic acid supplement in men and women with below average levels of high density lipoprotein cholesterol. J Am Coll Nutr. 2005;24:189-99.

70. Kawakami Y, Yamanaka-Okumura H, Naniwa-Kuroki Y, Sakuma M, Taketani Y, Takeda E. Flaxseed oil intake reduces serum small dense low-density lipoprotein concentrations in Japanese men: a randomized, double blind, crossover study. Nutr J. 2015;14:39.

71. Harper CR, Edwards MC, Jacobson TA. Flaxseed oil supplementation does not affect plasma lipoprotein concentration or particle size in human subjects. J Nutr. 2006;136:2844-8.

72. Liu Y, Zhang L, Song H, Ji G. Update on berberine in nonalcoholic fatty liver disease. Evid Based Complement Alternat Med. 2013;2013:308134.

73. Pirillo A, Catapano AL. Berberine, a plant alkaloid with lipid- and glucoselowering properties: from in vitro evidence to clinical studies. Atherosclerosis. 2015;243:449-61.

74. Joffe $M$, Robertson $\mathrm{A}$. The potential contribution of increased vegetable and fruit consumption to health gain in the European Union. Public Health Nutr. 2001;4:893-901.

75. Rimm EB, Ascherio A, Giovannucci E, Spiegelman D, Stampfer MJ, Willett WC. Vegetable, fruit, and cereal fiber intake and risk of coronary heart disease among men. JAMA. 1996;275:447-51.
76. Wang L, Bordi PL, Fleming JA, Hill AM, Kris-Etherton PM. Effect of a moderate fat diet with and without avocados on lipoprotein particle number, size and subclasses in overweight and obese adults: a randomized, controlled trial. J Am Heart Assoc. 2015;4:e001355.

77. Park E, Edirisinghe I, Burton-Freeman B. Avocado fruit on postprandial markers of cardio-metabolic risk: a randomized controlled dose response trial in overweight and obese men and women. Nutrients. 2018;10:E1287.

78. Basu A, Fu DX, Wilkinson M, Simmons B, Wu M, Betts NM, Du M, Lyons TJ. Strawberries decrease atherosclerotic markers in subjects with metabolic syndrome. Nutr Res. 2010;30:462-9.

79. Basu A, Betts NM, Nguyen A, Newman ED, Fu D, Lyons TJ. Freeze-dried strawberries lower serum cholesterol and lipid peroxidation in adults with abdominal adiposity and elevated serum lipids. J Nutr. 2014;144:830-7.

80. Zunino SJ, Parelman MA, Freytag TL, Stephensen CB, Kelley DS, Mackey BE, Woodhouse LR, Bonnel EL. Effects of dietary strawberry powder on blood lipids and inflammatory markers in obese human subjects. Br J Nutr. 2012; 108:900-9.

81. Zunino SJ, Peerson JM, Freytag TL, Breksa AP, Bonnel EL, Woodhouse LR, Storms DH. Dietary grape powder increases IL-1 beta and IL-6 production by lipopolysaccharide-activated monocytes and reduces plasma concentrations of large LDL and large LDL-cholesterol particles in obese humans. Br J Nutr. 2014;112:369-80.

82. Toth PP, Patti AM, Nikolic D, Giglio RV, Castellino G, Biancucci T, Geraci F, David S, Montalto G, Rizvi A, Rizzo M. Bergamot reduces plasma lipids, Atherogenic small dense $L D L$, and subclinical atherosclerosis in subjects with moderate hypercholesterolemia: a 6 months prospective study. Front Pharmacol. 2016;6:299.

83. Gliozzi M, Carresi C, Musolino V, Palma E, Muscoli C, Vitale C, Gratteri S, Muscianisi G, Janda E, Muscoli S. The effect of bergamot-derived polyphenolic fraction on LDL small dense particles and non alcoholic fatty liver disease in patients with metabolic syndrome. Adv Biol Chem. 2014;4: 129.

84. Galletti F, Fazio V, Gentile M, Schillaci G, Pucci G, Battista F, Mercurio V, Bosso G, Bonaduce D, Brambilla N. Efficacy of a nutraceutical combination on lipid metabolism in patients with metabolic syndrome: a multicenter, double blind, randomized, placebo controlled trial. Lipids Health Dis. 2019; 18:66.

85. de Souza RGM, Schincaglia RM, Pimentel GD, Mota JF. Nuts and human health outcomes: a systematic review. Nutrients. 2017;9:E1311.

86. Del Gobbo LC, Falk MC, Feldman R, Lewis K, Mozaffarian D. Effects of tree nuts on blood lipids, apolipoproteins, and blood pressure: systematic review, meta-analysis, and dose-response of 61 controlled intervention trials. Am J Clin Nutr. 2015;102:1347-56.

87. López-Uriarte P, Bulló M, Casas-Agustench P, Babio N, Salas-Salvadó J. Nuts and oxidation: a systematic review. Nutr Rev. 2009;67:497-508.

88. Yucesan FB, Orem A, Kural BV, Orem C, Turan I. Hazelnut consumption decreases the susceptibility of LDL to oxidation, plasma oxidized LDL level and increases the ratio of large/small LDL in normolipidemic healthy subjects. Anadolu Kardiyol Derg. 2010;10:28-35.

89. Hernandez-Alonso P, Salas-Salvado J, Baldrich-Mora M, Mallol R, Correig X, Bullo M. Effect of pistachio consumption on plasma lipoprotein subclasses in pre-diabetic subjects. Nutr Metab Cardiovasc Dis. 2015;25:396-402.

90. Chen CY, Holbrook M, Duess MA, Dohadwala MM, Hamburg NM, Asztalos BF, Milbury PE, Blumberg JB, Vita JA. Effect of almond consumption on vascular function in patients with coronary artery disease: a randomized, controlled, cross-over trial. Nutr J. 2015;14:61.

91. Almario RU, Vonghavaravat $V$, Wong R, Kasim-Karakas SE. Effects of walnut consumption on plasma fatty acids and lipoproteins in combined hyperlipidemia. Am J Clin Nutr. 2001;74:72-9.

92. Lee Y, Berryman CE, West SG, Chen CYO, Blumberg JB, Lapsley KG, Preston AG, Fleming JA, Kris-Etherton PM. Effects of dark chocolate and almonds on cardiovascular risk factors in overweight and obese individuals: a randomized controlled-feeding trial. J Am Heart Assoc. 2017;6:e005162.

93. Damasceno NR, Sala-Vila A, Cofan M, Perez-Heras AM, Fito M, RuizGutierrez V, Martinez-Gonzalez MA, Corella D, Aros F, Estruch R, Ros E. Mediterranean diet supplemented with nuts reduces waist circumference and shifts lipoprotein subfractions to a less atherogenic pattern in subjects at high cardiovascular risk. Atherosclerosis. 2013;230: 347-53.

94. Holligan SD, West SG, Gebauer SK, Kay CD, Kris-Etherton PM. A moderate-fat diet containing pistachios improves emerging markers of cardiometabolic 
syndrome in healthy adults with elevated LDL levels. Br J Nutr. 2014;112 744-52

95. Martin RC, Aiyer HS, Malik D, Li Y. Effect on pro-inflammatory and antioxidant genes and bioavailable distribution of whole turmeric vs curcumin: similar root but different effects. Food Chem Toxicol. 2012;50: 227-31.

96. Lee HY, Kim SW, Lee GH, Choi MK, Chung HW, Lee YC, Kim HR, Kwon HJ, Chae HJ. Curcumin and Curcuma longa L extract ameliorate lipid accumulation through the regulation of the endoplasmic reticulum redox and ER stress. Sci Rep. 2017;7:6513.

97. Panahi Y, Khalili N, Hosseini MS, Abbasinazari M, Sahebkar A. Lipidmodifying effects of adjunctive therapy with curcuminoids-piperine combination in patients with metabolic syndrome: results of a randomized controlled trial. Complement Ther Med. 2014;22:851-7.

98. Abdollahi E, Momtazi AA, Johnston TP, Sahebkar A. Therapeutic effects of curcumin in inflammatory and immune-mediated diseases: a nature-made jack-of-all-trades? J Cell Physiol. 2018;233:830-48.

99. Karimian MS, Pirro M, Majeed M, Sahebkar A. Curcumin as a natural regulator of monocyte chemoattractant protein-1. Cytokine Growth Factor Rev. 2017:33:55-63.

100. Mollazadeh H, Cicero AFG, Blesso CN, Pirro M, Majeed M, Sahebkar A. Immune modulation by curcumin: the role of interleukin-10. Crit Rev Food Sci Nutr. 2019;59:89-101.

101. Momtazi AA, Derosa G, Maffioli P, Banach M, Sahebkar A. Role of microRNAs in the therapeutic effects of Curcumin in non-Cancer diseases. Mol Diagn Ther. 2016;20:335-45.

102. Panahi $Y$, Kianpour $P$, Mohtashami R, Jafari R, Simental-Mendía LE, Sahebkar A. Efficacy and safety of Phytosomal Curcumin in non-alcoholic fatty liver disease: a randomized controlled trial. Drug Res. 2017;67:244-51.

103. Rezaee R, Momtazi AA, Monemi A, Sahebkar A. Curcumin: a potentially powerful tool to reverse cisplatin-induced toxicity. Pharmacol Res. 2017;117: 218-27.

104. Iranshahi M, Sahebkar A, Takasaki M, Konoshima T, Tokuda H. Cancer chemopreventive activity of the prenylated coumarin, umbelliprenin, in vivo. Eur J Cancer Prev. 2009;18:412-5.

105. Sahebkar A. Molecular mechanisms for curcumin benefits against ischemic injury. Fertil Steril. 2010;94:e75-6.

106. Mahfouz MM, Zhou SQ, Kummerow FA. Curcumin prevents the oxidation and lipid modification of LDL and its inhibition of prostacyclin generation by endothelial cells in culture. Prostaglandins Other Lipid Mediat. 2009;90: 13-20.

107. Kang Q, Chen A. Curcumin eliminates oxidized LDL roles in activating hepatic stellate cells by suppressing gene expression of lectin-like oxidized LDL receptor-1. Lab Investig. 2009;89:1275.

108. Moohebati M, Yazdandoust S, Sahebkar A, Mazidi M, Sharghi-Shahri Z, Ferns G, Ghayour-Mobarhan M. Investigation of the effect of short-term supplementation with curcuminoids on circulating small dense low-density lipoprotein concentrations in obese dyslipidemic subjects: a randomized double-blind placebo-controlled cross-over trial. ARYA Atheroscler. 2014;10: 280.

109. Ng K-W, Cao Z-J, Chen H-B, Zhao Z-Z, Zhu L, Yi T. Oolong tea: a critical review of processing methods, chemical composition, health effects, and risk. Crit Rev Food Sci Nutr. 2018;58:2957-80.

110. Yang M-H, Wang C-H, Chen H-L. Green, oolong and black tea extracts modulate lipid metabolism in hyperlipidemia rats fed high-sucrose diet. J Nutr Biochem. 2001;12:14-20.

111. Shimada K, Kawarabayashi T, Tanaka A, Fukuda D, Nakamura Y, Yoshiyama M, Takeuchi K, Sawaki T, Hosoda K, Yoshikawa J. Oolong tea increases plasma adiponectin levels and low-density lipoprotein particle size in patients with coronary artery disease. Diabetes Res Clin Pract. 2004;65:227-34.

112. Moongngarm A, Saetung N. Comparison of chemical compositions and bioactive compounds of germinated rough rice and brown rice. Food Chem. 2010;122:782-8.

113. Araki R, Ushio R, Fujie K, Ueyama Y, Suzuki H, Nakata Y, Hashimoto K. Effect of partially-abraded brown rice consumption on body weight and the indicators of glucose and lipid metabolism in pre-diabetic adults: a randomized controlled trial. Clin Nutr ESPEN. 2017;19:9-15.

114. Crini G. Historical review on chitin and chitosan biopolymers. Environ Chem Lett. 2019:17:1623-43.

115. Rinaudo M. Chitin and chitosan: properties and applications. Prog Polym Sci. 2006:31:603-32.
116. Huang H, Zou Y, Chi H, Liao D. Lipid-modifying effects of chitosan supplementation in humans: a pooled analysis with trial sequential analysis. Mol Nutr Food Res. 2018;62:e1700842.

117. Baker W, Tercius A, Anglade M, White C, Coleman C. A meta-analysis evaluating the impact of chitosan on serum lipids in Hypercholesterolemic patients. Ann Nutr Metabol. 2009;55:368-74.

118. Rizzo M, Giglio RV, Nikolic D, Patti AM, Campanella C, Cocchi M, Katsiki N, Montalto G. Effects of chitosan on plasma lipids and lipoproteins: a 4-month prospective pilot study. Angiology. 2014;65:538-42.

119. Allerton T, Proctor D, Stephens J, Dugas T, Spielmann G, Irving B. I-Citrulline supplementation: impact on cardiometabolic health. Nutrients. 2018;10:921.

120. Mirenayat MS, Moradi S, Mohammadi H, Rouhani MH. Effect of L-Citrulline supplementation on blood pressure: a systematic review and meta-analysis of clinical trials. Curr Hypertens Rep. 2018;20:98.

121. Morita M, Sakurada M, Watanabe F, Yamasaki T, Ezaki H, Morishita K, Miyake T. Effects of oral L-citrulline supplementation on lipoprotein oxidation and endothelial dysfunction in humans with vasospastic angina. Immunol Endocr Metab Agents Med Chem. 2013;13:214-20.

122. Gentile M, Calcaterra I, Strazzullo A, Pagano C, Pacioni D, Speranza E, Rubba P, Marotta G. Effects of Armolipid plus on small dense LDL particles in a sample of patients affected by familial combined hyperlipidemia. Clin Lipidol. 2015;10:475-80.

\section{Publisher's Note}

Springer Nature remains neutral with regard to jurisdictional claims in published maps and institutional affiliations.
Ready to submit your research? Choose BMC and benefit from:

- fast, convenient online submission

- thorough peer review by experienced researchers in your field

- rapid publication on acceptance

- support for research data, including large and complex data types

- gold Open Access which fosters wider collaboration and increased citations

- maximum visibility for your research: over $100 \mathrm{M}$ website views per year

At BMC, research is always in progress.

Learn more biomedcentral.com/submissions 